\title{
Innate Memory T cells
}

\author{
Stephen C. Jameson ${ }^{1}$, You Jeong Lee, and Kristin A. Hogquist ${ }^{1}$ \\ Center for Immunology, University of Minnesota Medical School, Minneapolis, Minnesota, USA
}

\begin{abstract}
Memory T cells are usually considered to be a feature of a successful immune response against a foreign antigen, and such cells can mediate potent immunity. However, in mice, alternative pathways have been described, through which naïve $\mathrm{T}$ cells can acquire the characteristics and functions of memory $\mathrm{T}$ cells without encountering specific foreign antigen or the typical signals required for conventional $\mathrm{T}$ cell differentiation. Such cells reflect a response to the internal rather the external environment, and hence such cells are called innate memory T cells. In this review, we describe how innate memory subsets were identified, the signals that induce their generation and their functional properties and potential role in the normal immune response. The existence of innate memory $\mathrm{T}$ cells in mice raises questions about whether parallel populations exist in humans, and we discuss the evidence for such populations during human $\mathrm{T}$ cell development and differentiation.
\end{abstract}

\section{INTRODUCTION}

In-nate adjective $\backslash i-$ ' $n \bar{a} t,{ }^{\prime} i-, \backslash$

1. existing in, belonging to, or determined by factors present in an individual from birth: native, inborn <innate behavior>

2. belonging to the essential nature of something: inherent

3. originating in or derived from the mind or the constitution of the intellect rather than from experience

Merriam-Webster Online Dictionary (2014)

During the immune response to foreign antigens, stimulation of the TCR in the context of inflammation generates not only a large number of short-lived effector cells, but also a memory population that is maintained long term and forms the basis for efficient recall responses and protective immunity against many pathogens. However, numerous lines of evidence suggest this pathway is not the only way to generate $\mathrm{T}$ cells with memory-like phenotype and function. Various homeostatic cues can promote naïve $\mathrm{T}$ cells to acquire memory $\mathrm{T}$ cell characteristics in the apparent absence of foreign antigen induction. This conversion is especially marked for CD8+ T cells in mice and is driven by both engagement of the TCR with self-peptide/MHC ligands and response to various cytokines (including IL-2, IL-4, IL-7, and IL-15). The resulting memory-like cells—sometimes called "innate"

\footnotetext{
${ }^{1}$ Corresponding authors: james024@umn.edu; hogqu001@umn.edu.
} 
memory $\mathrm{T}$ cells - have enhanced response potential, including the ability to efficiently combat pathogens.

In this review, we will discuss the various pathways that yield innate memory $\mathrm{T}$ cells, their relationship to "true" antigen-driven memory cells, and the possible physiological roles. We will also explore the unresolved issue of whether the innate memory populations defined in mice have parallels in humans.

There have been numerous studies that have investigated memory-like cells in different experimental contexts, and this has led to a proliferation of names for these cells (see Fig. 1). We propose a rationalization of this nomenclature. As a first step, in this review, we will assign names for memory $\mathrm{T}$ cell populations as follows (also see Fig. 1):

Antigen-induced memory. These are also called "true" or "conventional" memory cells and are induced by TCR stimulation with foreign antigen, in the context of productive costimulatory and cytokine cues.

Innate memory cells. These are memory cells that are present in the steady state and NOT induced by TCR stimulation with foreign antigen and are comprised of two known populations:

- $\quad$ Lymphopenia-induced memory. This is a T cell population with memory phenotype that arises in environments where the number of T-lymphocytes falls below normal levels ( $\mathrm{T}$ cell lymphopenia). This population has also been called "homeostatic memory" or "lymphopenia-driven memory."

- $\quad$ IL-4-induced memory. This is a T cell population with memory phenotype that arises in response to high levels of the cytokine IL-4. Identified initially in gene deficient or mutant mice but, such cells have also observed in some normal mouse strains. This population has also been called "bystander memory" or "innate memory" in the literature. At present, this population has primarily been defined within the CD8 + T cell subset.

Naturally occurring antigen-specific, memory-like CD8+ T cells have been defined in the steady state in mice. The derivation of this population, called "virtual memory" $\mathrm{T}$ cells, is difficult to unambiguously define, but based on various characteristics, is thought to be composed of both lymphopenia- and IL-4-induced memory T cells.

\section{INNATE MEMORY T CELLS PRODUCED THROUGH RESPONSE TO LYMPHOPENIA}

\subsection{Identification of lymphopenia-induced memory $\mathrm{T}$ cells}

Some of the first evidence that memory $\mathrm{T}$ cells can arise without foreign antigen priming came from studies that were intended to test MHC dependence of naïve T cell homeostasis. One of the great advantages of studies on hematopoietic cells is the ease with which they can be transferred between animals. Hence, it would seem simple to test whether, for example, CD8+ T cells survive normally in MHC Class I-deficient (MHC-I ${ }^{-/}$) mice. However, such experiments quickly hit an experimental roadblock due to rejection issues- 
in this case, the robust response of MHC- $\mathrm{I}^{-/-}$host cells toward the "foreign" MHC Class I molecules on donor CD8+ T cells, with catastrophic consequences for the latter. This result can easily be misinterpreted as failure to survive (rather than active rejection), and such concerns continue to plague the literature. However, a seemingly simple solution to this problem is to thwart the host antidonor immune response by using host animals that lack $\mathrm{T}$ cells due either to genetic ablation of key factors in $\mathrm{T}$ cell generation or using acute depletion measures such as irradiation, anti-T cell antibody treatment, or use of chemotherapeutic drugs. As has been discussed (Singh \& Schwartz, 2006), this use of lymphopenic animal models has a long and distinguished history in immunology and has other appealing features in addition to preventing donor cell rejection-such as substantially better adoptive transfer efficiency in lymphopenic hosts, in which there is more "space" for those donor cells.

At face value, this approach performed nicely and yielded data supporting the idea that encounter with specific self-peptide/MHC molecules was critical for naïve T cell survival: various approaches showed that naïve CD4+ T cells transferred into Class II MHC-deficient $\left(\mathrm{MHC}-\mathrm{II}^{-/-}\right.$) lymphopenic hosts were present at notably lower numbers than cells transferred into wild-type lymphopenic hosts (Brocker, 1997; Kirberg, Berns, \& von Boehmer, 1997; Takeda, Rodewald, Arakawa, Bluethmann, \& Shimizu, 1996), and similar findings were reported for CD8+ T cells transferred into normal versus MHC- $\mathrm{I}^{-/-} \mathrm{T}-$ depleted hosts (Markiewicz et al., 1998; Nesic \& Vukmanovic, 1998). However, a key insight came from the realization that this was not simply a matter of naïve $\mathrm{T}$ cell survival, but that the donor cells were proliferating in some of these hosts-specifically, in the animals expressing normal self-peptide/MHC molecules (Bender, Mitchell, Kappler, \& Marrack, 1999; Beutner \& MacDonald, 1998; Cho, Rao, Ge, Eisen, \& Chen, 2000; Clarke \& Rudensky, 2000; Ernst, Lee, Chang, Sprent, \& Surh, 1999; Goldrath \& Bevan, 1999; Kieper \& Jameson, 1999; Murali-Krishna \& Ahmed, 2000; Muranski, Chmielowski, \& Ignatowicz, 2000; Viret, Wong, \& Janeway, 1999).

These studies were remarkable not only for the demonstration that naïve $\mathrm{T}$ cells could be provoked into proliferation in the absence of TCR engagement with foreign antigen but because further investigation revealed that these proliferating naïve $\mathrm{T}$ cells had changed in phenotype and function, such that they resembled memory T cells (Cho et al., 2000; Clarke \& Rudensky, 2000; Ernst et al., 1999; Goldrath \& Bevan, 1999; Kieper \& Jameson, 1999; Murali-Krishna \& Ahmed, 2000; Muranski et al., 2000). This conversion included upregulation of the markers CD44, CD122 (IL-2Rbeta), and Ly6-C (but not acute activation markers such as CD69 or CD25) and effector responses such as the ability to rapidly produce IFN- $\gamma$ upon TCR stimulation and, in the case of CD8+ T cells, acquisition of cytolytic function (Clarke \& Rudensky, 2000; Ernst et al., 1999; Goldrath \& Bevan, 1999; Goldrath, Bogatzki, \& Bevan, 2000; Kieper \& Jameson, 1999; Murali-Krishna \& Ahmed, 2000; Muranski et al., 2000; Fig. 2).

This proliferation and differentiation processes have been given various names, including homeostatic proliferation, homeostatic expansion, lymphopenia-dependent proliferation, and lymphopenia-induced proliferation. The use of the word "homeostatic" can be misleading since this process involves changes in the naïve $\mathrm{T}$ cell differentiation state (and hence is not 
actually regenerating the naïve T cell pool). Also, the phrase "homeostatic proliferation" is more commonly used to describe the replacement proliferation observed for memory $\mathrm{T}$ cells. For clarity, we will use the terms lymphopenia-induced proliferation and lymphopeniainduced memory $T$ cells in this review (Fig. 2), but the reader should be forewarned of the diverse nomenclature used in the literature.

This phenotypic and functional similarities between lymphopenia- and antigen-induced memory cells were found to extend to their transcriptional profiles-which suggested convergence in the gene expression characteristics with time (Goldrath, Luckey, Park, Benoist, \& Mathis, 2004). Nevertheless, some features of lymphopenia-induced memory CD8+ T cells distinguish these cells from foreign antigen-induced memory cells-most notably, the expression of a4-integrin (CD49d), a component of the homing receptors VLA-4 and LPAM (Haluszczak et al., 2009). CD49d is expressed at low levels on naïve $\mathrm{CD} 8+\mathrm{T}$ cells and is elevated upon priming, leading to CD49 $\mathrm{d}^{\text {hi }}$ phenotype of foreign antigen-induced memory CD8+ T cells. In contrast, lymphopenia-induced memory CD8+ T cells are CD49d $\mathrm{d}^{\text {lo }}$ (in some cases, CD49d expression is even lower than the naïve cells) (Haluszczak et al., 2009). The functional relevance of this difference in CD49d levels and how well this marker alone can be used to reliably discern the origin of memory-phenotype $\mathrm{T}$ cells is less clear. Other studies show that gene expression for various chemokines and chemokine receptors differ between antigen- and lymphopenia-induced memory CD8+ T cells, including elevated expression of CCR7 and CXCR5 in the latter population (Cheung, Yang, \& Goldrath, 2009).

\subsection{The role of TCR specificity on lymphopenia-induced innate memory $T$ cell generation}

The factors driving lymphopenia-induced proliferation and concomitant appearance of memory phenotype have been intensely studied and extensively reviewed (Goldrath, 2002; Jameson, 2002; Min \& Paul, 2005; Sprent \& Surh, 2011; Surh \& Sprent, 2008). As discussed above, the role of TCR engagement with self-pMHC ligands was apparent from the earliest studies-however, further work illustrated that TCR specificity greatly impacts the extent of lymphopenia-induced proliferation.

At one extreme, there are cells that undergo very extensive proliferation in response to lymphopenia, contrasting with the slow proliferative pace of most $\mathrm{T}$ cells. This is especially marked in the CD4+ pool when the response is assessed in a chronic lymphopenic host and is accompanied by significant upregulation of activation/memory markers and acquisition of full effector functions (e.g., ability to rapidly produce IFN- $\gamma$ and IL-2). This response, called "spontaneous" or "endogenous" proliferation (Min, Foucras, Meier-Schellersheim, \& Paul, 2004; Min et al., 2003; Min \& Paul, 2005), is materially different from the slow "homeostatic" proliferation in terms of the factors that drive these processes, including the requirements for cytokines and costimulatory cues (Gudmundsdottir \& Turka, 2001; Hagen et al., 2004; Kieper et al., 2005; Min \& Paul, 2005; Surh \& Sprent, 2008; Wu et al., 2004). More detailed investigations showed that this rapid "endogenous" proliferation is actually dependent on the commensal microbiota: the response disappears in germ-free lymphopenic mice, and this extensive proliferation is not seen with several TCR transgenic CD4+ T cell clones (which nevertheless undergo slow lymphopenia-induced proliferation) (Kieper et al., 
2005). Further, this rapid proliferative response does not actually require lymphopenia at all - since it can be provoked in CD4+ T cells transferred into TCR transgenic hosts (which can have a roughly normalsized $\mathrm{T}$ cell compartment, but drastically curtailed diversity) (Kieper et al., 2005; Min \& Paul, 2005; Min, Yamane, Hu-Li, \& Paul, 2005; Surh \& Sprent, 2008). Current models suggest that these rapidly dividing cells are making a response to foreign antigen from commensal microbes, which are not adequately controlled in the lymphopenic host. This response depends on complexity of the microbiota, since germ-free mice reconstituted with a defined minimally diverse gut flora did not support rapid proliferation (Kieper et al., 2005). This might suggest direct recognition of commensal microbial antigens, but the idea that $\mathrm{T}$ cells respond to self-antigens induced by commensal colonization has not been ruled out. However, since this response has all the hallmarks of a bona fide "foreign" antigen response, we consider memory-like cells produced in this rapid proliferation response to be "true" not innate memory cells. Hence, we will not discuss this response directly further-but the fact that this rapid proliferation response is a component of many published studies can complicate straightforward interpretation.

There are also $\mathrm{T}$ cells that appear to undergo no proliferation or conversion to memory phenotype when exposed to a lymphopenic environment. This was most apparent when TCR transgenic T cells were investigated: some clones undergo robust proliferation and naïve $\rightarrow$ innate memory conversion (for example, TCR transgenic OT-I, P14, and 2C CD8+ T cells; AND, HA, and SM-1 CD4+ T cells), while others remain for extended periods of time as nondividing naïve T cells (e.g., the H-Y and pmel-1 CD8+ T cells; 5C.C7, OT-II, and Marilyn CD4+ T cells), with some models lying between these extremes (Barthlott, Kassiotis, \& Stockinger, 2003; Ferreira, Barthlott, Garcia, Zamoyska, \& Stockinger, 2000; Johnson \& Jameson, 2010; Kieper, Burghardt, \& Surh, 2004; Le Campion et al., 2002; Min et al., 2004; Moses, Thorstenson, Jameson, \& Khoruts, 2003; Troy \& Shen, 2003; Fig. 2).

Interestingly, there exists a correlation between naïve $\mathrm{T}$ cells expression of the molecule CD5 and their capacity to undergo lymphopenia-induced proliferation or respond to other homeostatic cues (Cho, Kim, Surh, \& Sprent, 2010; Ge, Bai, Jones, Eisen, \& Chen, 2004; Johnson \& Jameson, 2010; Kieper et al., 2004; Palmer, Mahajan, Chen, Irvine, \& Lauffenburger, 2011; Smith et al., 2001). Various studies (including analysis of TCR transgenic and normal mice) indicate that CD5 levels are directly proportional to the intensity of TCR signaling by self-peptide/MHC ligands, leading to the conclusion that cells with higher CD5 expression also have higher affinity for self-ligands. This is very hard to demonstrate, however, since a given TCR could bind to multiple self-peptide/MHC complexes, making it difficult to measure the aggregate strength of those interactions. It is also possible that the CD5 levels reflect the density of relevant self-peptide/MHC ligands (not the affinity of the TCR for those complexes) (Hogquist \& Jameson, 2014).

In any case, the finding that naïve T cells with elevated CD5 expression levels are most responsive to lymphopenia leads to the concept that the response to lymphopenia will skew the TCR repertoire, such that some clones (those from the CD5hi population) will expand to greater frequency than other clones (originating from the CD5lo pool) (Fig 1). It has been proposed that competition for peptide/MHC ligands may balance repertoire skewing among the CD4+ T cell population (Min et al., 2004), while other studies suggest that the FoxP3+ 
CD4+ Treg can promote greater TCR diversity among CD8+ T cells responding to lymphopenia (Winstead et al., 2010). Hence, TCR repertoire narrowing during lymphopenia-induced proliferation may depend on the exact composition of the responding T cell pool.

But what is the nature of the TCR signal that drives lymphopenia-induced innate memory $\mathrm{T}$ cell generation? Little is understood about biochemical aspects of this signal, but genetic manipulation studies have helped define key pathways in the signals for lymphopeniainduced proliferation and accompanying differentiation of naïve $\mathrm{T}$ cells into memory-like cells. Work from Zamoyska's lab showed that loss of the key TCR signaling kinase Lck led to a profound block of proliferation in typical lymphopenic hosts (Seddon, Legname, Tomlinson, \& Zamoyska, 2000; Seddon \& Zamoyska, 2002a). Lck expression was less critical for T cell survival, which forms an interesting contrast with most studies that show qualitatively similar requirements for lymphopenia-induced proliferation and naïve $\mathrm{T}$ cell maintenance (Seddon et al., 2000; Seddon \& Zamoyska, 2002b). Very recent studies showed that the loss of the phosphatase PTPN2 - which can inhibit both Lck and Fyn activationleads to more vigorous lymphopenia-induced proliferation in naïve T cells (Wiede, La Gruta, \& Tiganis, 2014; Wiede et al., 2011). In addition, loss of the SIT adapter protein also enhances lymphopenia-induced proliferation and generation of memory-phenotype T cells (Posevitz et al., 2008) — while initial studies reached the confusing conclusion that SIT was needed for effective TCR signaling, further analysis revealed that with more physiological TCR stimulation, proximal signaling events were enhanced by SIT deficiency or knockdown (Arndt et al., 2011). Hence, changes in TCR signal sensitivity may impact induction or extent of naïve $\mathrm{T}$ cell response to lymphopenia. Interestingly, $\mathrm{T}$ cells bearing mutant TCRs that are unable to efficiently induce $\mathrm{NF \kappa B}$ activation were shown to be unable to produce antigen-induced memory cells following encounter with potent foreign antigens, yet could generate lymphopenia-induced memory cells similar to normal $\mathrm{T}$ cells of the same specificity (Knudson, Hamilton, Daniels, Jameson, \& Teixeiro, 2013; Teixeiro et al., 2009). Hence, the TCR signals resulting from binding to low affinity self-peptide/MHC ligands that are important for lymphopenia-induced proliferation may be qualitatively (as well as quantitatively) different from TCR signals induced by encounter with high-affinity foreign antigen/MHC ligands.

The Class II MHC binding molecule LAG-3 can play an inhibitory role in regulating lymphopenia-induced proliferation, but this effect is not limited to CD4+ T cells but also applies to the response of CD8+ T cells (Workman \& Vignali, 2005). Interestingly, CD8+ T cells isolated from Class II MHC-deficient mice (but not CD4+-deficient mice) show substantially greater lymphopenia-induced proliferation, and this can be further augmented by LAG-3 blockade (Do, Valujskikh, Vignali, Fairchild, \& Min, 2012). While the basis for these effects is currently unclear, they highlight the possibility that TCR independent interactions with MHC molecules may also be important in control of lymphopenia-induced proliferation and innate memory $\mathrm{T}$ cell differentiation.

However, how critical TCR engagement and signaling is for lymphopenia-induced proliferation is also influenced by the degree of lymphopenia. Studies using T cells lacking expression of Lck or both the Lck and Fyn kinases revealed that cells could proliferate in 
profoundly immunodeficient hosts (while their response to less severe lymphopenic environments was prevented) (Seddon \& Zamoyska, 2002a). Proliferation of TCR signaling impaired T cells was highly sensitivity to IL-7 blockade-implying that TCR signals become less important when there is ample IL-7 available.

\subsection{The role of IL-7 in lymphopenia-induced innate memory $T$ cell generation}

A priori, the role of lymphopenia might serve to provide better access to competitive resources, or might remove cells/factors that restrained lymphopenia-induced proliferation. Regarding the former idea, it became clear that lymphopenia-induced proliferation, and the accompanying conversion of naïve to innate memory cells, required the cytokine IL-7. Like TCR interaction with self-pMHC, IL-7 is intimately involved in naïve T cell survival, during steady state in lymphoreplete conditions (Sprent \& Surh, 2011; Surh \& Sprent, 2008; Takada \& Jameson, 2009). Yet IL-7 is also critical for lymphopenia-induced proliferation, as shown by severely reduced response of CD8+ and CD4+ T cells in $I l 7^{-1-}$ host animals (Goldrath et al., 2002; Schluns, Kieper, Jameson, \& Lefrancois, 2000; Tan et al., 2002; Fig. 2). Indeed, increased IL-7 availability might be the essential feature of lymphopenia, as indicated by the ability of excess IL-7 to induce proliferation and memory conversion in the absence of lymphopenic conditions (Boyman, Ramsey, Kim, Sprent, \& Surh, 2008; Kieper et al., 2002; Min et al., 2005). At the same time, these findings do not exclude a potential role for other cytokines. The best studied of these are the $\gamma \mathrm{c}$-cytokines (i.e., those that signal through receptors that utilize the common- $\gamma$ chain, which includes IL-2, IL-4, IL-7, IL-9, IL-15, and IL-21). High or sustained levels (including those that can be achieved using complexes of cytokines with antibodies or soluble receptors) of the cytokines IL-2, IL-4, IL-7, and IL-15 have been shown to promote the proliferation and naïve to memory phenotype conversion of $\mathrm{T}$ cells, similar to the response to lymphopenia, but in lymphoreplete animals (Boyman, Kovar, Rubinstein, Surh, \& Sprent, 2006; Kamimura \& Bevan, 2007; Morris et al., 2009). Also, numerous studies have shown that IL-15 is required for maintenance of memory CD8+ T cells (Schluns \& Lefrancois, 2003; Surh \& Sprent, 2008), and while IL-15 is not required to initiate lymphopenia-induced memory $\mathrm{T}$ cell formation, there is evidence that IL-15 supports CD8+ T cell expansion and maintenance following the initial response to lymphopenia (Li et al., 2011; Sandau, Winstead, \& Jameson, 2007). Hence, while IL-7 may be required for naïve T cell survival and initiation of lymphopenia-induced memory production, other cytokines may augment this response. Indeed, we will return to the unique role of IL-4 in a later section.

IL-7R signals are important for expression of antiapoptotic factors (including Bcl-2 and Mcl-1) but also to promote normal naïve T cell metabolism (Carrette \& Surh, 2012; Jiang et al., 2005). These signals may be important for $\mathrm{T}$ cell maintenance during the response to lymphopenia, but it is not clear that they are sufficient to provoke the proliferative step. Studies on the role of the mTOR kinase (which is activated through PI3K/Akt signaling) suggest that IL-7 induces mTOR activity and that mTOR is essential for the proliferative response of CD8+ T cells toward lymphopenic cues (Li et al., 2011). Furthermore, those studies suggest that mTOR signaling leads to upregulation of the T-bet transcription factor, which in turn increases expression of CD122, allowing cells to more efficiently respond to IL-15. This pathway can continue, such that IL-15 signals promote increased expression of 
Eomes (a T-box factor related to T-bet). In this way, it is proposed that a cascade of signals leads to rebalance of the T-bet/Eomes balance (similarly to that proposed for differentiation of true memory CD8+ T cells; Rao, Li, Odunsi, \& Shrikant, 2010), eventually leading to the situation in which both factors are expressed. We will return to this point in context of the unusual expression of T-box factors observed in IL-4-induced innate memory cells.

In naïve T cells, IL-7R signaling induces its own downregulation - an unusual feature, since signals through many cytokine receptors leads to increased not decreased receptor expression (Park et al., 2004). This effect is thought to allow for "sharing" of the cytokine by the entire naïve $\mathrm{T}$ cell pool-the concept being that cells that have recently responded to IL-7 will have decreased capacity to bind the cytokine compared to cells that have been deprived of IL-7R signals (Mazzucchelli \& Durum, 2007; Park et al., 2004). IL-7 itself is produced by stromal cells in lymphoid tissues, and is thought to be produced at similar levels regardless of lymphocyte numbers. Hence, it is possible that one of the essential features of lymphopenia-induced memory formation is that the proportional increase in availability of IL-7 allows T cells to continue responding to this cytokine even with decreased IL-7R expression since the typical competition with other $\mathrm{T}$ cells is reduced (Dummer, Ernst, LeRoy, Lee, \& Surh, 2001; Mazzucchelli \& Durum, 2007; Park et al., 2004; Fig 1). Studies using over-expression of IL-7 correlate with this concept.

\subsection{Relationship between naïve $T$ cell proliferation and generation of innate memory cells}

Various models using mouse $\mathrm{CD} 8+\mathrm{T}$ cells indicate that division induced by exposure to lymphopenia (or enhanced exposure to homeostatic cues such as IL-7, which mimic the lymphopenic environment) generates cells that have upregulated markers (including CD44 and CD122) and functions (IFN- $\gamma$ production, cytolysis) similar to true memory CD8+ T cells (Jameson, 2002; Sprent \& Surh, 2011; Surh \& Sprent, 2008). Furthermore, gene expression analysis suggests lymphopenia induces CD8+ T cell differentiation that aligns with the changes observed during the foreign antigen response (Goldrath et al., 2004). It is much less clear that this occurs for mouse CD4+ T cells. While initial studies suggested lymphopenia induces differentiation of naïve CD4+ T cells similarly to CD8+ T cells, "endogenous" proliferation - the process discussed earlier, which is thought to involve proliferation toward foreign antigens released from the gut microbiota-masked the response of slowly proliferating cells (Min \& Paul, 2005; Surh \& Sprent, 2008; Tchao \& Turka, 2012). Indeed, more refined analysis showed that the slow proliferation of naïve CD4+ T cells often involves little if any change in CD44 expression and minimal induction of effector traits such as ability to quickly release IFN- $\gamma$ (Le Campion et al., 2002; Martin, Bourgeois, Dautigny, \& Lucas, 2003; Min et al., 2003, 2004; Seddon \& Zamoyska, 2002a). Indeed, some studies suggest CD4+ T cell responses to lymphopenia can lead to a form of anergy (Tanchot, Le Campion, Leaument, Dautigny, \& Lucas, 2001). A complicating feature is the difference in the pace of lymphopenia-induced proliferation by CD4+ and CD8+ T cells-although both are "slow" compared to a foreign antigen response, CD8+ T cells typically divide more rapidly and extensively than CD4+ T cells. Even with this taken into account however, published reports suggest minimal or at least incomplete acquisition of memory-like traits by CD4+ T cells undergoing lymphopenia-induced proliferation. 
Hence, it is not clear that cell division in response to lymphopenia always causes naïve $\rightarrow$ memory $\mathrm{T}$ cell conversion. The reverse-that acquisition of memory phenotype necessarily involves naïve $\mathrm{T}$ cell proliferation — seems more consistent, but a potential exception has been observed in which $\mathrm{T}$ cells (in nonlymphopenic animals) were induced to delete the transcription factor Foxp1 (Feng et al., 2011): this led Foxp1-deleted cells to begin proliferating, and upregulate $\mathrm{CD} 44$ and acquire IFN- $\gamma$ production competence, but, interestingly Foxp1-deleted cells that had not divided also showed similar phenotypic and functional changes (Feng et al., 2011; Skon \& Jameson, 2011).

Hence, although the links between lymphopenia and the generation of memory-phenotype $\mathrm{T}$ cells has been illustrated in many experimental systems, there may be exceptions-which complicate straightforward correlations in nonexperimental systems (e.g., analysis of humans).

\section{INNATE MEMORY CD8+ T CELLS INDUCED BY IL-4}

While the innate memory cells produced in response to homeostatic cues have been studied for nearly 15 years, in 2009, we defined a quite distinct population of innate memory T cells. Bystander or $I L$-4-induced memory $\mathrm{T}$ cells are a population of memory-phenotype $\mathrm{T}$ cells that arise in response to exogenous IL-4 secreted from PLZF+ $a \beta$ or $\gamma \delta$ NKT cells (Fig. 3; Lee, Jameson, \& Hogquist, 2011). In many cases where this population has been observed, IL-4-induced memory $\mathrm{T}$ cells can first be detected in the thymus, this population being derived from recently matured CD8+ CD4- (and, to a lesser extent, CD4+ CD8-) single positive (SP) thymocytes (Lee et al., 2011). IL-4-induced memory T cells are distinguished from antigen- and lymphopenia-induced memory CD8+ T cells in that they express the transcription factor Eomes but not T-bet (Lee et al., 2011). Cells of this phenotype were first identified in the thymus of $i t k$-deficient mice, where they were referred to as innate $C D 8+T$ cells (Andreotti, Schwartzberg, Joseph, \& Berg, 2010; Berg, 2007) but the role of IL-4, produced by bystander $\mathrm{T}$ cells, was not appreciated for several years. When it was, the term bystander memory was used because mixed bone marrow chimeras showed that CD8+ T cells themselves did not need to be gene deficient in order to acquire this memory phenotype - but they did need to be able to respond to extrinsic IL-4 produced by other T cells. IL-4induced memory cells were subsequently found in many other transgenic and gene-deficient mice (Table 1). NKT cells were ultimately identified as the cell that produces IL-4 in the steady state to drive IL-4-induced memory CD8+ T cells (Lee et al., 2011). Recently, it was discovered that IL-4-induced memory CD8+ T cells are present to varying degrees in the thymus and periphery of normal mice in the steady state (Lee, Holzapfel, et al., 2013; Weinreich et al., 2010).

\subsection{A subset of NKT cells produces IL-4 to induce innate memory CD8+ T cell differentiation}

Many studies have now demonstrated a key role for PLZF+ T cells as the source of IL-4 that promotes the development of IL-4-induced memory CD8+ T cells (Table 1 and Fig. 3). PLZF is a member of the BTB/POZ family of transcription factors that is essential for the development of invariant NKT (iNKT) cells (Kovalovsky et al., 2008; Savage et al., 2008). iNKT cells are lipid-specific, CD1d-restricted T cells that utilize a canonical TCR Va14 
chain paired with limited $\mathrm{V} \beta$ chains ( $\mathrm{V} \beta 2$, 7, and 8 ) and can produce IL-4 when activated (Engel \& Kronenberg, 2014). PLZF is also critical for development of a subset of $\gamma \delta$ T cells preferentially expressing $\mathrm{V} \gamma 1.1$ and $\mathrm{V} \delta 6.3$ chains, referred to by some as " $\gamma \delta \mathrm{NKT}$ cells" as they express PLZF and NK receptors and can produce IL-4 (Felices et al., 2009; Lees, Ferrero, \& MacDonald, 2001).

PLZF+ cells are normally rare and/or not activated to produce IL-4 in some mouse strains, including the well-studied C57BL/6 strain. However, PLZF+ cells can be expanded and/or activated by various genetic alterations (Table 1). Since the first report describing bystander memory CD8+ T cells in KLF2-deficient mice (Weinreich et al., 2010), a total of 15 different genetic alterations have been shown to influence the generation or activation of IL-4-producing PLZF+ T cells, and subsequently to increase memory-phenotype CD8+ T cells expressing Eomes (Table 1). Mixed BM chimera experiments confirmed the cell extrinsic effects of IL-4 in most of these cases (Table 1).

One principle that has emerged from these studies is that it is not merely the total number of PLZF+ NKT cells that impacts CD8+ memory development but also their differentiation state (Fig. 4). Historically, the development of iNKT cells was thought to follow a linear maturation process, wherein CD44 ${ }^{\text {low }} \mathrm{NK} 1.1-$ immature cells secrete IL-4 and mature into CD $44^{\text {high }} \mathrm{NK} 1.1^{-}$and CD44 ${ }^{\text {high }} \mathrm{NK} 1.1^{+}$cells that produce IFN- $\gamma$ (Bendelac, Savage, \& Teyton, 2007). This paradigm, however, could not explain the emerging effector phenotypes of iNKT cells in various gene-deficient mice, especially T-bet and GATA-3. In the absence of T-bet, NK1.1 negative iNKT cells were expanded, whereas GATA-3-deficient mice reciprocally favored the development of NK1.1 positive iNKT cells and had a paucity of "immature" NK1.1 negative cells (Kim et al., 2006; Lee, Holzapfel, et al., 2013). Also, a newly identified IL-17-producing subset was NK1.1 negative, but had terminally differentiated effector features (Michel et al., 2008). Finally, IL-4-producing cells that were NK1.1 - IL-17RB + were unable to develop into NK1.1+ IFN- $\gamma$-producing cells (Watarai et al., 2012) strongly challenging the idea that all NK1.1 negative cells mature into NK1.1 positive cells. Thus currently, a lineage differentiation model prevails, where T-bet, GATA-3, and ROR $\gamma$ t, together with PLZF, direct a thymic multipotent precursor to NKT1 (PLZFlow), NKT2 (PLZFigh), and NKT17 (PLZF ${ }^{\text {int }}$ ) effector fates, with the potential to produce IFN- $\gamma$, IL-4, or IL-17, respectively (Fig. 3; Constantinides \& Bendelac, 2013; Engel \& Kronenberg, 2014; Lee, Holzapfel, et al., 2013). Studies using IL-4 reporter (KN2) mice that express huCD2 from the IL-4 locus, showed that PLZF ${ }^{\text {high }}$ NKT2 cells were positive for huCD2, particularly in BALB/c mice, indicating that only this subset produces IL-4 continuously in vivo (Dickgreber et al., 2012; Lee, Holzapfel, et al., 2013). Thus, genetic differences that alter either the number or activation of NKT2 cells can lead to an increase in IL-4 memory CD8+ T cells. For example, in KLF2 KO mice, the number of NKT2 cells was expanded dramatically, while in T-bet KO mice the number of iNKT cells was not increased, but the effector fate of iNKT cells was redirected from NKT1 into NKT2 and NKT17 lineages (Lee, Holzapfel, et al., 2013). In normal mice, a multitude of genetic polymorphisms could presumably be contributing to NKT heterogeneity, however, between six different inbred strains, the level of IL-4 produced by NKT2 cells was tightly correlated 
with the development of IL-4 memory CD8+ T cells (Lee, Holzapfel, et al., 2013), suggesting that this is the key factor.

\subsection{Factors that regulate the generation of PLZF+ NKT cells and IL-4-induced memory CD8+ T cells}

At this point, it remains unclear whether the 15 factors listed in Table 1 interact in a common pathway to regulate the effector fate and/or activation of PLZF+ cells. ITK is one of the Tec family of nonreceptor tyrosine kinases and SLP76 is an adaptor molecule; the tyrosine residue at position 145 of SLP76 is required for ITK recruitment to the linker for activation of T cells (LAT)/SLP76 adapter complex following TCR stimulation (Atherly et al., 2006; Jordan et al., 2008; Nayar et al., 2012). Both ITK $^{-1-}$ and SLP76 ${ }^{\text {Y145F }}$ mice have a distinct population of memory-phenotype CD8 + SP thymocytes expressing Eomes (Atherly et al., 2006; Jordan et al., 2008) resulting from an expansion of IL-4-producing $\gamma \delta$ NKT cells (Felices et al., 2009). a $\beta$ NKT cells were rather decreased in these mice and unequal BM chimera experiments showed the cell extrinsic nature of Eomes+ CD8+ T cell development (Jordan et al., 2008; Nayar et al., 2012; Weinreich et al., 2010). However, a cell intrinsic aspect of ITK-deficient CD8+ T cells was also suggested, in which ITK-dependent IRF4 upregulation suppresses Eomes expression in CD8+ T cells and loss of ITK or IRF4 facilitate CD8+ T cells to express Eomes independent of IL-4 (Nayar et al., 2012).

Another adaptor molecule, Nedd4-family interacting protein 1 (Ndfip1) affects innate CD8+ memory T cell differentiation in another way. Ndfip1 is a cofactor for E3 ubiquitin ligases, and deficiency in this factor leads to elevated IL-4 expression. Unlike other studied systems, however, perturbations of the number or differentiation of iNKT or $\gamma \delta$ NKT cells was not apparent, and the induction of innate memory-phenotype CD8+ T cells was observed in the periphery but not the thymus. In this model, it appears that conventional peripheral CD4+ T cells overproduce IL-4 in the absence of Ndfip1 (Oliver et al., 2006) (Kurzweil et al., 2014). This raises the intriguing possibility that bystander CD8+ T cells may develop into Eomes+ memory CD8+ $\mathrm{T}$ cells during the course of strong type 2 immune responses.

CREB binding protein (CBP) is a component of histone/protein acetyltransferases, which interact with more than $50 \mathrm{~T}$ cell transcriptional regulators, and deficiency in this factor leads to generation of cells with characteristics of IL-4-induced innate memory CD8+ T cells (Fukuyama et al., 2009; Weinreich et al 2010). CBP deficiency leads to defective TCR signaling after TCR stimulation similar to those of ITK-/- or Id3-/- T cells, suggesting a common mechanism that altered signal strength might favor the survival of PLZF expressing cells, that otherwise might be negatively selected (Lee et al., 2011).

Krüppel-like factor 2 (KLF2) is a transcription factor well characterized for its regulation of $\mathrm{T}$ cell migration. KLF2 deficient mice show grossly normal $\mathrm{T}$ cell development, but exhibit an expansion of T cells expressing PLZF, many of which were iNKT cells, and which produce IL-4 (Weinreich et al. 2009, 2010). KLF2 deficiency is not thought to alter T cell repertoire selection, and the increased representation of PLZF+ cells in klf2-l- mice might be due arise because KLF2 can suppress c-Myc expression, which is required for iNKT cell proliferation (Lee et al., 2011). 
Id3 is a dominant negative regulator of $\mathrm{E}$ proteins highly expressed on lymphocytes. It restricts the development of $\alpha \beta$ and $\gamma \delta$ NKT cells, as its deficiency drives the expansion of both $\alpha \beta$ and $\gamma \delta$ NKT (Alonzo et al., 2010; Ueda-Hayakawa et al., 2009; Verykokakis, Boos, Bendelac, Adams, et al., 2010; Verykokakis, Boos, Bendelac, \& Kee, 2010). However, NKT cell differentiation is also strongly affected. For example, NKT2 cells predominate among Id3-deficient a $\beta$ NKT cells (D’Cruz et al., 2014; Verykokakis et al., 2013), and IL-4 produced by such cells resulted in a dramatic accumulation of IL-4 memory CD8+ T cells (Verykokakis, Boos, Bendelac, \& Kee, 2010; Weinreich et al., 2010). Whether Id3 acts downstream of Itk/SLP76 signals or they represent independent regulatory pathways that control iNKT cell differentiation remains unclear. The T-bet transcription factor directs differentiation and IFNg secretion by Th1 CD4 T cells, memory CD8 T cells, NK and NKT1 cells. In the absence of T-bet, the development of NKT1 cells is blocked and it was reciprocally favored the development of NKT2 and NKT17 cells. As a result, expanded NKT2 cells provided more IL-4 at steady state, which facilitates the development of innate CD8 T cells (Lee et al., 2013). KLF13 - another transcription factor in the Krüppel-like family, plays a distinct role from its cousin KLF2. KLF13 deficiency in BALB/c mice was discovered to result in a complete loss of IL-4 memory CD8+ T cells, which was not cell intrinsic (Lai et al., 2011). These mice had a lower frequency of iNKT cells, accompanied with downregulation of PLZF, suggesting a loss of NKT2 cells and relative increase in NKT1 and NKT17. As a result, IL-4 memory CD8+ T cells did not develop, thus reversing the phenotype of BALB/c mice. On the B6 background, KLF13 deficiency resulted in no apparent phenotype, which may be because B6 mice have already a relatively small fraction of NKT cells producing IL-4. Recently, KLF13 was shown to promote IL-4 expression through direct binding to the IL-4 promoter (Kwon et al., 2014), although, again, whether KLF13 is downstream of Itk/SLP76, and/or interacts with Id3 to regulate NKT effector fate, remains to be determined.

Jarid2 is a component of histone methyltransferase complexes. In Jarid2 deficient mice, the frequency of thymic iNKT cells among total thymocytes was slightly decreased, but the frequency of the NKT2 subset was significantly expanded among iNKT cells (Pereira et al., 2014). Jarid 2 was shown to directly bind the PLZF locus and induce H3K9me3 deposition, and hence may serve to repress PLZF expression in developing iNKT cells (Pereira et al., 2014).

Homotypic interactions between SLAM family receptors SLAMF1 and SLAMF6 on DP thymocytes, which signal through the adaptor SAP, are required for NKT cell positive selection. Another SLAM family member, Ly9 (SLAMF3 or CD229), is highly expressed on NKT cells and seems to be a negative regulator of NKT development (Sintes et al., 2013). The frequencies of iNKT cells were increased in Ly9-deficient B6 and BALB/c mice, but the difference was marginal in B6 mice, and Eomes+ CD8+ T cells were only increased in BALB/c mice. BCAT $^{\text {Tg }}$ mice on a C57BL/6 background had increased PLZF ${ }^{\text {high }}$ iNKT cells that overproduced IL-4, and such mice developed high numbers of Eomes+ CD8+ T cells (Sharma et al., 2012). $\gamma \delta$ NKT cells were not investigated in $\mathrm{Ly}^{-/}{ }^{-}$or $\beta \mathrm{CAT}^{\mathrm{Tg}}$ mice.

Most of the above models show perturbations in $\alpha \beta$ or $\gamma \delta$ NKT cells. CIITA ${ }^{\text {Tg }}$ mice represent a slightly different, albeit equally interesting, scenario. DP thymocytes in CIITA ${ }^{\mathrm{Tg}}$ 
mice express MHC Class II, and this results in the positive selection of polyclonal Class IIrestricted CD4+ T cells that express PLZF (Choi et al., 2005; Lee et al., 2010; Li et al., 2005). Although this is a nonphysiologic phenomenon in mice, there is some evidence that human thymocytes express MHC Class II, particularly early in life, and these mice may represent a model of that. In the CIITA ${ }^{\mathrm{Tg}}$ mouse model, PLZF expression in CD4+ T cells requires SLAM family member signals, results in elevated IL-4 production and expansion of Eomes+ CD8+ T cells (Li et al., 2007; Min et al., 2011).

Additional evidence from mice suggests that there is a biased ontogenic window for the development of IL-4 memory CD8+ T cells. This comes from the study of Lin28b, which is a protein regulator of Let7 microRNAs, expressed on fetal hematopoietic stem cells in mice and humans (Yuan et al., 2012). When overexpressed in adult retroviral BM chimeras, Lin28b-expressing stem cells favored the development of innate B cells, suggesting that Lin28b is an essential regulator of "fetal type" hematopoiesis. Lin28b-expressing stem cells also gave rise to dramatically increased proportions of PLZF+ iNKT and CD4+ V $\gamma 1.1^{+}$ $\mathrm{V} \delta 6.3^{+} \gamma \delta \mathrm{T}$ cells. Like Id3-deficient iNKT cells, the iNKT population showed skewed differentiation with fewer NK1.1+ (NKT1) cells and more PLZFigh (NKT2/17) cells. Not surprisingly, they observed a strong increase in IL-4 memory CD8+ T cells in both GFP ${ }^{+}$ and $\mathrm{GFP}^{-}$thymocytes in Lin28b retroviral BM chimeras consistent with an IL-4-mediated bystander effect that is not cell intrinsic. Analogously, in BALB/c mice, both NKT2 cells and IL-4 memory CD8+ T cells are highest early in life and decrease starting at about 7 weeks of age (Lee, Holzapfel, et al., 2013).

All of the factors listed above have been shown to induce changes in the NKT compartment, leading to non-autonomous 'bystander' effects on the development of IL-4 induced memory CD8+ T cells. In addition, deficiency in two factors: $\mathbf{N F} \kappa \mathbf{B 1}$ and $\mathbf{B c l 1 1 b}$, lead to a cell autonomous increase in the development of innate memory CD8+ T cells in the thymus (Gugasyan et al. 2012; Hirose et al. 2014), although it is unclear whether these factors operate in the same or distinct pathways.

\subsection{Distinctions between IL-4- and lymphopenia-induced memory CD8+ T cells}

Compared to antigen- and lymphopenia-induced memory CD8+ T cells, the population that arises after exposure to IL-4 bears many unusual features (Fig. 1). A hallmark feature is the finding that IL-4 induces expression of Eomes but not T-bet in CD8+ T cells-this contrasts with lymphopenia-induced memory cells that express both T-bet and Eomes at higher levels than naïve T cells (Weinreich et al., 2009, 2010; Lee, Hamilton et al. 2013; Sosinowski et al. 2013).

Eomes is essential for development of all the phenotypic and functional memory-like characteristics of the IL-4-induced innate memory population, which include increased expression of CD44, CXCR3, CD122, and the ability to rapidly produce IFN- $\gamma$ (Weinreich et al., 2009, 2010). Several of these features can be induced by IL-4 in mature peripheral CD8+ T cells (Kurzweil et al., 2014; Nayar et al., 2012; Oliver, Stolberg, Chensue, \& King, 2012; Ventre et al., 2012; Weinreich et al., 2009), suggesting this is not purely a response of CD8+ SP thymocytes. Studies in which CD8+ T cells were exposed to IL-4 suggested that Eomes expression was induced in a STAT6-dependent pathway (Oliver et al., 2012; Ventre 
et al., 2012). The basis by which IL-4 promotes expression of Eomes without T-bet is unclear, but it is interesting to note that studies on lymphopenia-induced proliferation reported that blockade of mTOR led to an increased Eomes:T-bet ratio and slightly reduced expression of CD122 (Li et al., 2011), both which are features of IL-4-induced memory CD8+ T cells. So, it is possible that factors in the lymphopenic environment provoke mTOR activation and subsequent T-bet, CD122, and Eomes induction, while IL-4R signals may induce Eomes upregulation and memory differentiation without a requirement for mTOR and T-bet participation in that process (similar to the pathway observed when lymphopeniainduced proliferation occurs in the presence of the mTOR inhibitor Rapamycin) (Li et al., 2011). However, this situation may well be more complicated since other factors can induce Eomes expression, including TCF-1, which is activated by Wnt signaling (and by TCR and cytokine receptor signals), and is required for antigen-induced generation and persistence of memory CD8+ T cells (Zhou et al., 2010).

IL-4 signaling through STAT6 also invokes other unusual features in memory cells: compared to the antigen-induced population, IL-4-induced memory CD8+ T cells exhibit reduced expression of NKG2D (a receptor initially identified on NK cells, but which can costimulate CD8+ T cell responses) and the chemokine CCL5 (Ventre et al., 2012). In antigen-activated CD8+ T cells, exposure to IL-4 reduced cytolytic activity and utilization of NKG2D costimulation (Ventre et al., 2012). Notably, reduced expression of NKG2D was also observed on the IL-4-induced memory CD8+ T cells that arise spontaneously in BALB/c strain mice (Ventre et al., 2012).

It is currently unclear whether conversion of naïve T cells into IL-4-induced memory cells requires a TCR signal. Since IL-4-induced memory T cells typically arise from CD8+ SP cells in the thymus, it is experimentally difficult to address this issue, because encounter with self-peptide/MHC is a prerequisite for thymic positive selection.

Perhaps the most striking difference between lymphopenia- and IL-4-induced memory CD8+ T cells is not their phenotype but the location of the naïve $\rightarrow$ memory conversion: while current evidence suggests lymphopenia-induced memory chiefly occurs in peripheral lymphoid tissues, IL-4-induced memory cells have been most commonly described in the thymus (Lee et al., 2011). This may be a feature of the abundance of IL-4-producing PLZF+ cells in the thymus, and appears not to be an absolute rule, since studies using Ndfip1deficient mice showed appearance of IL-4-induced memory cells in the periphery but not the thymus (Kurzweil et al., 2014).

\section{INNATE MEMORY T CELLS IN NORMAL HOMEOSTASIS: "VIRTUAL MEMORY" T CELLS}

While work on lymphopenia-induced memory has relevance for situations of lymphopenia that accompany some infections and therapeutic treatments (see Section 4), it was less clear that innate memory cells would arise during normal physiology by this mechanism. However, several groups found that $\mathrm{T}$ cells transferred into neonatal mice undergo proliferative responses as if the environment was lymphopenic, and this correlates with the finding that the peripheral T cell compartment takes several weeks to "fill" to the levels seen 
in adult mice (Akue, Lee, \& Jameson, 2012; Le Campion et al., 2002; Min et al., 2003; Schuler, Hammerling, \& Arnold, 2004). This raised the possibility that neonatal lymphopenia might spark a physiological form of lymphopenia-induced proliferation and memory differentiation in the first waves of $\mathrm{T}$ cells leaving the thymus. Indeed, there is a significant population of memory-phenotype T cells (both CD4+ and CD8+) in normal unimmunized mice maintained under "specific pathogen free" (SPF) conditions. However, unlike the adoptive transfer systems discussed above, an inherent problem with trying to define the origin of these naturally occurring memory-like cells is the inability to define when they were generated and the cues that induced their appearance.

Although animals maintained in SPF conditions are protected from diverse mouse pathogens, they are exposed to many foreign antigens in the form of commensal and environmental microbes - any of these could provoke a bona fide immune response. It is noteworthy though that germ-free mice-which are not colonized by microbial flora-have a similar frequency of memory-phenotype CD8+ T cells (Haluszczak et al., 2009). Yet, even germ-free mice are exposed to foreign antigens in the form of food (including microbial products in the autoclaved feed). Some studies have taken this issue to the next level by generating "antigen-free" mice, germ-free mice which are maintained on a diet of chemically defined nutrients, ultrafiltered to eliminate complex macromolecules: while some early studies indicated that CD44 ${ }^{\text {hi }} \mathrm{T}$ cell frequency was reduced in such mice (Vos, Jones, \& Kruisbeek, 1992), more recent studies have found that CD4+ and CD8+ memoryphenotype $\mathrm{T}$ cells do arise in antigen-free mice, eventually reaching frequencies similar to those observed in germ-free and SPF mice (C. Surh, personal communication).

But what is the antigen specificity of these cells? Defining this is critical to understanding the basis for generation of this population and their potential role in subsequent immune responses. With the development of elegant techniques to enrich and characterize rare antigen-specific lymphocytes (which are typically in the range of 10-1000 cells per mouse) (Moon et al., 2007), it became possible to address this question. Peptide/MHC tetramerbased enrichment from unprimed SPF and even germ-free mice showed that the "naïve" precursor population is not entirely naïve in phenotype after all, but that 5-35\% of antigennaïve cells have a memory phenotype (Haluszczak et al., 2009). This population was termed virtual memory $\mathrm{CD} 8+\mathrm{T}$ cells, since it was recognized that these antigen-specific memory cells were produced in the absence of discernable encounter with specific foreign antigen (hence virtual rather than actual or true memory). It is not yet clear whether there is a CD4+ $\mathrm{T}$ cell counterpart to the population defined in CD8+ T cells. Since the initial description, virtual memory CD8+ T cells (defined using tetramers) have been demonstrated in several other models (Chiu, Martin, Stolberg, \& Chensue, 2013; La Gruta et al., 2010; Renkema, Li, Wu, Smithey, \& Nikolich-Zugich, 2014; Rudd et al., 2011; Sosinowski et al., 2013; Fig. 1).

Even though the definition of virtual memory cells includes the feature that these cells have specificity for a foreign antigen that has not been encountered, this is extremely difficult to prove. While the studies in germ-free and antigen-free mice may show that virtual memory $\mathrm{T}$ cells can arise in the absence of any encountered foreign antigen, the memory-phenotype $\mathrm{T}$ cells in a normal mouse might be innate memory cells or could be heterologous memory cells ( $\mathrm{T}$ cells specific for unknown foreign antigen $\mathrm{X}$, which happen to cross-react with 
foreign antigen $\mathrm{Y}$, being studied). Interestingly, however, the virtual memory population bears some phenotypic differences from antigen-induced memory CD8+ T cells-most noticeably, low expression of CD49d which, as discussed earlier, appears to serve as a marker to identify memory-phenotype cells that have been generated by lymphopenia or IL-4, rather than foreign antigen priming (Haluszczak et al., 2009; Lee, Hamilton, Akue, Hogquist, \& Jameson, 2013; Sosinowski et al., 2013), although there are some studies that suggest this phenotypic trait may be less clear with IL-4-induced memory CD8+ T cells (Sosinowski et al., 2013). In addition, it has been reported that virtual memory cells express slightly higher levels of CD122 than antigen-induced memory CD8+ T cells (Haluszczak et al., 2009; Sosinowski et al., 2013).

We showed that virtual memory $\mathrm{T}$ cells are essentially absent in neonatal C57BL/6 stain mice, but arise soon thereafter, their peak of generation corresponding to the period of lymphopenia in very young mice (Akue et al., 2012). Hence, it is likely that these cells correspond most closely with lymphopenia-induced proliferation. The generation (and/or maintenance) of virtual memory cells in C57BL/6 mice depends on IL-15 and on CD8 +aexpressing dendritic cells, and expression of CD122 and Eomes by the CD8+ T cell population (Sosinowski et al., 2013). This correlates nicely with the proposed pathway for generation of lymphopenia-induced memory cells, which includes induction of CD122 and Eomes as important steps in the process (Li et al., 2011). On the other hand, IL-4-induced memory CD8+ T cells appear in some normal mouse strains-most prominently BALB/c (Lai et al., 2011; Weinreich et al., 2010), and the frequency of virtual memory CD8+ T cells is severely reduced in IL-4R-deficient BALB/c mice (Lee, Holzapfel, et al., 2013; Weinreich et al., 2010). Even in C57BL/6 mice, deficiencies in IL-4R, IL-4, PLZF, or iNKT cells (all of which are involved in IL-4-induced innate memory CD8+ T cell generation) led to a reduction in the frequency of virtual memory cells (Akue et al., 2012; Sosinowski et al., 2013). Hence, it is quite likely that virtual memory $T$ cells arise by a combination of lymphopenia- and IL-4-driven mechanisms, the prevalence of one pathway or the other depending on the mouse strain.

Two conclusions arise from these findings-first, that generation of memory-phenotype cells by homeostatic mechanisms is not only a feature of extreme lymphopenia but also occurs during normal physiology. Second, that many (potentially all) of the memoryphenotype CD8+ $\mathrm{T}$ cells present in unprimed mice are not driven by foreign antigen stimulation (Chiu et al., 2013; Haluszczak et al., 2009; Lee, Hamilton et al. 2013; Lee et al., 2011; Sosinowski et al., 2013).

Interestingly, as well as appearing in very young animals, there is recent evidence that the populations of memory CD8+ T cells that accumulate in old mice have characteristics of virtual memory cells (Chiu et al., 2013; Renkema et al., 2014; Rudd et al., 2011). Since this population dominates in older animals (while the naïve $\mathrm{T}$ cell population dwindles), this may be of considerable significance for immune competence in the elderly. 


\section{THE ROLE OF INNATE MEMORY T CELLS IN IMMUNITY}

As has been discussed earlier, innate memory cells (including lymphopenia-induced, IL-4induced, and any other virtual memory cells) show several functional traits similar to their true memory counterparts. This has been especially well tested for CD8+ T cells, where the capacity of innate memory cells has been extensively tested in vitro and studied in various infectious disease, cancer, and autoimmune models.

\subsection{Functional properties of lymphopenia-induced memory cells}

Innate memory CD8+ T cells generated by lymphopenia perform similarly to true memory $\mathrm{T}$ cells in terms of rapid production of IFN- $\gamma$ and induction of cytolytic function upon stimulation in vitro. Testing the in vivo response following infection with the bacteria Listeria monocytogenes (LM), we found striking similarities between lymphopenia-induced and true memory cells in their protective function, which was markedly better than protection afforded by naïve T cells of the same specificity (Hamilton, Wolkers, Schoenberger, \& Jameson, 2006). Similarly, there is evidence that lymphopenia-induced memory CD8+ T cells can enhance the response to tumors (Dummer et al., 2002; Hu, Poehlein, Urba, \& Fox, 2002; Li et al., 2011; Wang et al., 2005). Some studies however, indicate that, while protective against pathogens, lymphopenia-induced memory cells were inferior to antigen-induced memory cells in terms of recall antigen-driven expansion-a situation that was magnified in competitive assays (Cheung et al., 2009). This correlated with an inability of lymphopenia-induced memory cells to relocate within the spleen during LM infection-while true memory cells moved from the $\mathrm{T}$ cell area to the marginal zone and red pulp, lymphopenia-induced memory cells did not (Cheung et al., 2009). Altered chemokine and chemokine receptor expression may underlay these differences, although the exact causes are not yet clear (Cheung et al., 2009). This might indicate that, in situations where both antigen- and lymphopenia-induced memory cells coexist, the former would be selectively expanded by antigen stimulation. Interestingly, the capacity of lymphopeniainduced memory CD8+ T cells to function in effective control of Listeria depended on the characteristics of the lymphopenic environment: specifically, a lack of all CD4+ T cells in the lymphopenic host led to generation of memory-like CD8+ T cells that showed normal in vitro effector functions, yet were markedly depressed in control of LM (Hamilton et al., 2006). Similarly, preventing CD40-CD40L interactions and reduction in inflammatory cues had no effect on the capacity of naïve CD8+ T cells to respond to lymphopenia (by proliferation and conversion to memory-like cells), but caused a reduction in their in vivo protective capacity (Hamilton \& Jameson, 2008). While the basis for these changes in pathogen-control functions is not fully resolved, it is interesting to note that antigen-induced memory CD8+ T cells are also functionally compromised by a lack of CD4+ T cell help (Shedlock \& Shen, 2003; Sun \& Bevan, 2003).

In addition to the antigen-specific function of innate memory $\mathrm{CD} 8+\mathrm{T}$ cells, there may also be an important nonspecific function. Memory CD8+ T cells can produce IFN- $\gamma$ not only in response to TCR engagement but also in response to inflammatory cytokines, including the combination of IL-12 and IL-18 (this response is shared by NK cells and some memory CD4+ T cells). Lymphopenia-induced memory CD8+ $\mathrm{T}$ cells also display this trait 
(Hamilton et al., 2006), raising the possibility that these cells can contribute to IFN- $\gamma$ production during the early inflammatory phase of an immune response.

The functional properties of lymphopenia-induced memory CD4+ T cells have had relatively less attention. As mentioned earlier, the "endogenous proliferation" response of some CD4+ T cells produces cells with strong capacity for IFN- $\gamma$ production and may contribute to immune protection-yet this response is induced by the presence of commensal microbes, and hence may well be specific for foreign antigens (making this an antigen-induced or "true" memory population). The functional properties of CD4+ T cells undergoing the slow "homeostatic" proliferation have not been carefully explored, but there is less evidence for an enhanced ability to produce IFN- $\gamma$, compared to naïve T cells ( $\mathrm{Le}$ Campion et al., 2002; Martin et al., 2003; Min et al., 2003, 2004; Seddon \& Zamoyska, 2002a; Tanchot et al., 2001), and even some evidence for depressed effector functions (Tanchot et al., 2001).

The systems used to study lymphopenia-induced memory model these responses in highly lymphopenic environments: when might this such strongly lymphopenic situations occur outside the laboratory? Lymphopenia is induced in a variety of clinical settings, including chemotherapy and radiotherapy for cancer, and conditioning for organ transplant. Indeed, there is evidence for lymphopenia-induced memory formation in both of these situations, from experimental models. Conditioning with nonmyeloablative radiation was one of the chief approaches used in the experiments demonstrating lymphopenia-induced memory and, in the context of cancer therapy, there is evidence that the $\mathrm{T}$ cell response to lymphopenia can be harnessed to augment the antitumor response. Indeed, induction of profound lymphopenia has become a valuable element in use of adoptive $\mathrm{T}$ cell transfer immunotherapy approaches (Dudley et al., 2002; Klebanoff, Khong, Antony, Palmer, \& Restifo, 2005).

\subsection{Functional properties of IL-4-induced memory CD8+ T cells}

Compared to naïve cells of the same specificity, IL-4-induced memory CD8+ T cells acquired the capacity to produce IFN- $\gamma$ in response to IL-12 and IL-18, or TCR stimulation, and showed superior expansion after infection with antigen bearing LM (Weinreich et al., 2010). Compared to antigen-induced true memory cells, however, IL-4-stimulated memory CD8+ T cells showed decreased expression of NKG2D and CCL5 with less cytolytic activity (Ventre et al., 2012). Also BALB/c CD8+ T cells respond poorly to IL-12 and IL-18 stimulation to produce IFN- $\gamma$ compare to those of B6 mice, which was attributed to decreased induction of IL-12 and IL-18 receptors (Bou Ghanem, Nelson, \& D'Orazio, 2011). Based on these observations, it has been suggested that IL-4 memory CD $8+T$ cells have functional superiority over antigen inexperienced naïve CD8+ T cells, but that IL-4induced memory CD8+ $\mathrm{T}$ cells are less effective against pathogens compared to antigeninduced true memory cells (Ventre et al., 2012). These conclusions resonate with the altered expression of trafficking molecules and suboptimal reactivity proposed for lymphopeniainduced memory cells (Cheung et al., 2009).

One of the more surprising features of IL-4-induced memory T cells is that they are well equipped for production of IFN- $\gamma$-in other words, a Type- 2 cytokine (IL-4) drives 
generation of cells poised for making a Type- 1 cytokine (IFN- $\gamma$ ). It is possible that IL-4 exposure early in CD8 $+\mathrm{T}$ cell differentiation (i.e., during completion of thymic development) prevents acquisition of Tc2 (i.e., Th2-like CD8+ T cells) functional properties. However, studies that induced IL-4 production during the neonatal period led to CD8+ T cells that exacerbated allergic immune responses (Dubois et al., 2010), so this aspect of the properties of IL-4-induced memory cells awaits considerable further investigation.

\subsection{Functional properties of virtual memory CD8+ T cells}

Analysis of virtual memory $\mathrm{T}$ cells is complicated by the fact that, since these cells are derived from unmanipulated mice, the frequency of $\mathrm{T}$ cells with a given antigen specificity is very low. We circumvented this problem by using mice carrying a fixed TCR- $\beta$ chain, providing an increased frequency of cells specific for a designated antigen $\left(\mathrm{OVA} / \mathrm{K}^{\mathrm{b}}\right)$ but still within a diverse polyclonal pool (Lee, Hamilton et al. 2013). Studies with this model showed that VM cells share many features with antigen-induced memory cells during the in vivo and in vitro response to antigen: both were similarly capable of antigen-specific protection against LM infection, and both populations excelled compared to naïve T cells in the rapid kinetics of their in vivo response. Similar outcomes were observed using a different approach involving a $\beta \mathrm{TCR}$ transgenic CD8+ T cells that spontaneously acquire memory phenotype (Sosinowski et al., 2013). However, differences were noted between antigeninduced and virtual memory CD8+ T cells-among them that virtual memory cells displayed a reduced capacity to produce IFN- $\gamma$ in response to short term TCR stimulation (Lee, Hamilton et al. 2013). This characteristic mirrors that observed in an earlier study (Haluszczak et al., 2009). Nevertheless, virtual and antigen-induced memory CD8+ T cells were equally capable of producing IFN- $\gamma$ following IL-12/IL-18 stimulation. The basis for this difference in IFN- $\gamma$ production characteristics is unknown. In addition, virtual and antigen-induced memory cells differed in the subset characteristics of the "secondary memory" population induced by antigen encounter in vivo. These features suggest that naïve and virtual memory cells will contribute to distinct memory subsets following a "primary" immune response (Lee, Hamilton et al. 2013).

Recent studies show that virtual memory CD8+ T cells accumulate with age (Chiu et al., 2013; Renkema et al., 2014; Rudd et al., 2011). Intriguingly, this appears to selectively enrich CD8+ T cells with high avidity for the unencountered foreign antigen, presumably due to enhanced maintenance of $\mathrm{T}$ cells showing optimal interactions with selfpeptide/MHC (Rudd et al., 2011). On the other hand, virtual memory CD8+ T cells that accumulate in aged TCR transgenic mice showed compromised function, in that they showed impaired expansion (and greater susceptibility to apoptotic death) when stimulated through the TCR, yet showed robust proliferation in response to the homeostatic cytokine IL-15 (Renkema et al., 2014). Hence, in the elderly, such aged virtual memory cells may contribute to immune dysfunction.

\section{INNATE MEMORY CELLS IN HUMANS?}

Defining the origins of memory populations in laboratory mice is difficult, even though these animals are genetically identical and raised in defined housing conditions in the absence of infections by various normal mouse pathogens. The problem is even harder for 
studies with humans. Determining whether a population of memory-like cells in humans actually arise due to foreign antigen encounter or are innate memory cells has no clear resolution yet.

One potentially valuable insight into this question is the availability of umbilical cord blood, isolated during childbirth, and containing a rich resource for various blood cells, including circulating lymphocytes. Since establishment of the T cell compartment in newborn humans is much more advanced than that in newborn mice, there is already a prominent population of $\mathrm{T}$ cells in cord blood. It is generally agreed that these cells are nearly all naïve in phenotype - with regard to the markers typically employed, this would be the CD45RA+ CD45RO-ve phenotype, compared to CD45RA-ve, CD45RO+ phenotype that is prototypical for antigen-induced human memory $\mathrm{T}$ cells. At first glance, this would imply that innate memory cells are not a prominent population in immunologically naïve humans, and this has been the general conclusion from such data.

Intriguingly, however, analysis of fetal human tissues suggests a different story. Studies over 20 years ago showed a clear population of memory-phenotype $\mathrm{T}$ cells in the spleen and cord blood of premature births, accounting for $10-25 \%$ of CD4+ and CD8+ T cell populations (Byrne, Stankovic, \& Cooper, 1994). This population became much more prominent closer to the end of gestation, and the authors confirmed that such cells were virtually absent from full-term cord blood. Another study reached a similar conclusion, and also reported that up to $20 \%$ of human fetal CD8 + SP thymocytes of splenic CD8+ T cells expressed Eomes (Min et al., 2011). That report also found that up to 10\% of human fetal CD4SP thymocytes and $15 \%$ of CD4+ splenic T cells expressed PLZF and acquired innate characteristics (Lee et al., 2010), suggesting that this environment might support IL-4-induced memory T cell generation. Hence, there may be parallels between mice and humans in the appearance of such cells during thymic differentiation. Eomes-expressing CD8+ T cells from fetal human spleen rapidly produced IFN- $\gamma$ after in vitro stimulation and it was suggested that these $\mathrm{T}$ cells might provide protective immunity during the neonatal period (Min et al., 2011). What becomes of this population as pregnancy ends is unclear: it is possible that these cells die, become sequestered in other tissue sites, or are maintained but become overrun by the high frequency of naïve $\mathrm{T}$ cells coming from thymic differentiation. Something similar happens (albeit on a less dramatic scale) as naïve T cells arise in the weeks following birth in micethe number of virtual memory $\mathrm{T}$ cells does not change, but their percentage drops markedly (Akue et al., 2012).

Still, determining the origin and function of these memory-phenotype fetal human T cells is difficult. For example, the studies mentioned earlier showed that memory-phenotype fetal CD4+ T cells were typically CD25+. These cells probably correspond to a population of fetal Treg, which have been shown to be distinct from the Treg that develop after birth (Mold \& McCune, 2012). Whether the memory-phenotype CD8+ T cells are also a unique feature of fetal development is unclear.

Innate memory cells would not automatically need to arise before or at birth: Since there is evidence in mice that IL-4 can induce mature naïve CD8+ T cells to acquire innate characteristics in peripheral lymphoid tissues (Kurzweil et al., 2014), it is also possible that 
bystander memory $\mathrm{CD} 8+\mathrm{T}$ cells might arise in atopic individuals in whom elevated IL-4 expression is sustained. Likewise, the findings that most memory-phenotype CD8+ T cells in aged mice bear virtual memory traits holds open the idea that such cells may arise in elderly humans.

Recent studies on human $\mathrm{T}$ cells made the remarkable discovery that CD4+ T cells specific for unencountered antigens were frequently of memory phenotype-i.e., in subjects that tested seronegative for exposure to a given pathogen, CD4+ T cells specific for an antigen from that pathogen contained a large fraction of memory-phenotype cells ( $\mathrm{Su} \&$ Davis, 2013; Su, Kidd, Han, Kotzin, \& Davis, 2013). Those authors concluded that these cells arose from crossreactivity with environmental antigens-i.e., heterologous memory-rather than such cells being innate memory $\mathrm{T}$ cells. This was in part based on the absence of memorylike $\mathrm{T}$ cells in cord blood (discussed above), but also because some predicted epitopes from environmental microbes could be found that could be recognized as cross-reactive antigens. However, the concept that for nearly all tested unexposed antigens there exist an environmental antigen counterpart for TCR cross-reactivity seems unlikely.

In order to resolve such issues, further work is needed to define the gene expression and epigenetic characteristics of innate versus antigen-induced memory $\mathrm{T}$ cells-if a number of traits can be identified, this should provide a tool to differentiate the origins of memory $\mathrm{T}$ cells produced in these different ways - and allow for the significance of innate memory $\mathrm{T}$ cells in humans to be determined.

\section{References}

Akue AD, Lee JY, Jameson SC. Derivation and maintenance of virtual memory CD8 T cells. Journal of Immunology. 2012; 188:2516-2523.

Alonzo ES, Gottschalk RA, Das J, Egawa T, Hobbs RM, Pandolfi PP, et al. Development of promyelocytic zinc finger and ThPOK-expressing innate gamma delta T cells is controlled by strength of TCR signaling and Id3. Journal of Immunology. 2010; 184:1268-1279.

Andreotti AH, Schwartzberg PL, Joseph RE, Berg LJ. T-cell signaling regulated by the Tec family kinase, Itk. Cold Spring Harbor Perspectives in Biology. 2010; 2:a002287. [PubMed: 20519342]

Arndt B, Krieger T, Kalinski T, Thielitz A, Reinhold D, Roessner A, et al. The transmembrane adaptor protein SIT inhibits TCR-mediated signaling. PLoS One. 2011; 6:e23761. [PubMed: 21957439]

Atherly LO, Lucas JA, Felices M, Yin CC, Reiner SL, Berg LJ. The Tec family tyrosine kinases Itk and Rlk regulate the development of conventional CD8+ T cells. Immunity. 2006; 25:79-91. [PubMed: 16860759]

Barthlott T, Kassiotis G, Stockinger B. T cell regulation as a side effect of homeostasis and competition. The Journal of Experimental Medicine. 2003; 197:451-460. [PubMed: 12591903]

Bendelac A, Savage PB, Teyton L. The biology of NKT cells. Annual Review of Immunology. 2007; 25:297-336.

Bender J, Mitchell T, Kappler J, Marrack P. CD4(+) T cell division in irradiated mice requires peptides distinct from those responsible for thymic selection. Journal of Experimental Medicine. 1999; 190:367-374. [PubMed: 10430625]

Berg LJ. Signalling through TEC kinases regulates conventional versus innate CD8 (+) T-cell development. Nature Reviews. Immunology. 2007; 7:479-485.

Beutner U, MacDonald HR. TCR-MHC class II interaction is required for peripheral expansion of CD4 cells in a T cell-deficient host. International Immunology. 1998; 10:305-310. [PubMed: 9576618] 
Bou Ghanem EN, Nelson CC, D'Orazio SE. T cell-intrinsic factors contribute to the differential ability of CD8+ T cells to rapidly secrete IFN-gamma in the absence of antigen. Journal of Immunology. $2011 ; 186: 1703-1712$.

Boyman O, Kovar M, Rubinstein MP, Surh CD, Sprent J. Selective stimulation of T cell subsets with antibody-cytokine immune complexes. Science. 2006; 311:1924-1927. [PubMed: 16484453]

Boyman O, Ramsey C, Kim DM, Sprent J, Surh CD. IL-7/anti-IL-7 mAb complexes restore T cell development and induce homeostatic T Cell expansion without lymphopenia. Journal of Immunology. 2008; 180:7265-7275.

Brocker T. Survival of mature CD4 T lymphocytes is dependent on major histo-compatibility complex class II-expressing dendritic cells. Journal of Experimental Medicine. 1997; 186:1223-1232. [PubMed: 9334361]

Broussard C, Fleischacker C, Horai R, Chetana M, Venegas AM, Sharp LL, et al. Altered development of CD8+ T cell lineages in mice deficient for the Tec kinases Itk and Rlk. Immunity. 2006; 25:93104. [PubMed: 16860760]

Byrne JA, Stankovic AK, Cooper MD. A novel subpopulation of primed T cells in the human fetus. Journal of Immunology. 1994; 152:3098-3106.

Carrette F, Surh CD. IL-7 signaling and CD127 receptor regulation in the control of T cell homeostasis. Seminars in Immunology. 2012; 24:209-217. [PubMed: 22551764]

Cheung KP, Yang E, Goldrath AW. Memory-like CD8+ T cells generated during homeostatic proliferation defer to antigen-experienced memory cells. Journal of Immunology. 2009; 183:33643372.

Chiu BC, Martin BE, Stolberg VR, Chensue SW. Cutting edge: Central memory CD8 T cells in aged mice are virtual memory cells. Journal of Immunology. 2013; 191:5793-5796.

Cho JH, Kim HO, Surh CD, Sprent J. T cell receptor-dependent regulation of lipid rafts controls naive CD8+ T cell homeostasis. Immunity. 2010; 32:214-226. [PubMed: 20137986]

Cho BK, Rao VP, Ge Q, Eisen HN, Chen J. Homeostasis-stimulated proliferation drives naive T cells to differentiate directly into memory T cells. The Journal of Experimental Medicine. 2000; 192:549-556. [PubMed: 10952724]

Choi EY, Jung KC, Park HJ, Chung DH, Song JS, Yang SD, et al. Thymocyte-thymocyte interaction for efficient positive selection and maturation of CD4 T cells. Immunity. 2005; 23:387-396. [PubMed: 16226504]

Clarke SR, Rudensky AY. Survival and homeostatic proliferation of naive peripheral CD4+ T cells in the absence of self peptide:MHC complexes. Journal of Immunology. 2000; 165:2458-2464.

Constantinides MG, Bendelac A. Transcriptional regulation of the NKT cell lineage. Current Opinion in Immunology. 2013; 25:161-167. [PubMed: 23402834]

D'Cruz LM, Stradner MH, Yang CY, Goldrath AW. E and Id proteins influence invariant NKT cell sublineage differentiation and proliferation. Journal of Immunology. 2014; 192:2227-2236.

Dickgreber N, Farrand KJ, van Panhuys N, Knight DA, McKee SJ, Chong ML, et al. Immature murine NKT cells pass through a stage of developmentally programmed innate IL-4 secretion. Journal of Leukocyte Biology. 2012; 92:999-1009. [PubMed: 22941735]

Do JS, Valujskikh A, Vignali DA, Fairchild RL, Min B. Unexpected role for MHC II-peptide complexes in shaping CD8 T-cell expansion and differentiation in vivo. Proceedings of the National Academy of Sciences of the United States of America. 2012; 109:12698-12703. [PubMed: 22802622]

Dubois A, Deruytter N, Adams B, Kanda A, Delbauve S, Fleury S, et al. Regulation of Th2 responses and allergic inflammation through bystander activation of CD8+ T lymphocytes in early life. Journal of Immunology. 2010; 185:884-891.

Dudley ME, Wunderlich JR, Robbins PF, Yang JC, Hwu P, Schwartzentruber DJ, et al. Cancer regression and autoimmunity in patients after clonal repopulation with antitumor lymphocytes. Science. 2002:1076514.

Dummer W, Ernst B, LeRoy E, Lee D, Surh C. Autologous regulation of naive T cell homeostasis within the T cell compartment. Journal of Immunology. 2001; 166:2460-2468. 
Dummer W, Niethammer AG, Baccala R, Lawson BR, Reisfeld RA, Theofilopoulos AN. T cell homeostatic proliferation elicits effective anti-tumor autoimmunity. The Journal of Clinical Investigation. 2002; 110:185-192. [PubMed: 12122110]

Engel I, Kronenberg M. Transcriptional control of the development and function of Valpha14i NKT cells. Current Topics in Microbiology and Immunology. 2014; 381:51-81. [PubMed: 24839184]

Ernst B, Lee DS, Chang JM, Sprent J, Surh CD. The peptide ligands mediating positive selection in the thymus control T cell survival and homeostatic proliferation in the periphery. Immunity. 1999; 11:173-181. [PubMed: 10485652]

Felices M, Yin CC, Kosaka Y, Kang J, Berg LJ. Tec kinase Itk in gammadeltaT cells is pivotal for controlling IgE production in vivo. Proceedings of the National Academy of Sciences of the United States of America. 2009; 106:8308-8313. [PubMed: 19416854]

Feng X, Wang H, Takata H, Day TJ, Willen J, Hu H. Transcription factor Foxp1 exerts essential cellintrinsic regulation of the quiescence of naive T cells. Nature Immunology. 2011; 12:544-550. [PubMed: 21532575]

Ferreira C, Barthlott T, Garcia S, Zamoyska R, Stockinger B. Differential survival of naive CD4 and CD8 T cells. Journal of Immunology. 2000; 165:3689-3694.

Fukuyama T, Kasper LH, Boussouar F, Jeevan T, van Deursen J, Brindle PK. Histone acetyltransferase CBP is vital to demarcate conventional and innate CD8+ T-cell development. Molecular and Cellular Biology. 2009; 29:3894-3904. [PubMed: 19433445]

Ge Q, Bai A, Jones B, Eisen HN, Chen J. Competition for self-peptide-MHC complexes and cytokines between naive and memory CD8+ T cells expressing the same or different $\mathrm{T}$ cell receptors. Proceedings of the National Academy of Sciences of the United States of America. 2004; 101:3041-3046. [PubMed: 14976256]

Goldrath AW. Maintaining the status quo: T-cell homeostasis. Microbes and Infection. 2002; 4:539545. [PubMed: 11959509]

Goldrath AW, Bevan MJ. Low-affinity ligands for the TCR drive proliferation of mature CD8+ T cells in lymphopenic hosts. Immunity. 1999; 11:183-190. [PubMed: 10485653]

Goldrath AW, Bogatzki LY, Bevan MJ. Naive T cells transiently acquire a memory-like phenotype during homeostasis-driven proliferation. The Journal of Experimental Medicine. 2000; 192:557564. [PubMed: 10952725]

Goldrath AW, Luckey CJ, Park R, Benoist C, Mathis D. The molecular program induced in T cells undergoing homeostatic proliferation. Proceedings of the National Academy of Sciences of the United States of America. 2004; 101:16885-16890. [PubMed: 15548615]

Goldrath AW, Sivakumar PV, Glaccum M, Kennedy MK, Bevan MJ, Benoist C, et al. Cytokine requirements for acute and basal homeostatic proliferation of naive and memory CD8+ T cells. The Journal of Experimental Medicine. 2002; 195:1515-1522. [PubMed: 12070279]

Gordon SM, Carty SA, Kim JS, Zou T, Smith-Garvin J, Alonzo ES, et al. Requirements for eomesodermin and promyelocytic leukemia zinc finger in the development of innate-like CD8+ T cells. Journal of Immunology. 2011; 186:4573-4578.

Graham DB, Bell MP, McCausland MM, Huntoon CJ, van Deursen J, Faubion WA, et al. Ly9 (CD229)-deficient mice exhibit T cell defects yet do not share several phenotypic characteristics associated with SLAM- and SAP-deficient mice. Journal of Immunology. 2006; 176:291-300.

Gudmundsdottir H, Turka LA. A closer look at homeostatic proliferation of CD4+ T cells: Costimulatory requirements and role in memory formation. Journal of Immunology. 2001; 167:3699-3707.

Gugasyan R, Horat E, Kinkel SA, Ross F, Grigoriadis G, Gray D, et al. The NF-kappaB1 transcription factor prevents the intrathymic development of CD8 T cells with memory properties. The EMBO Journal. 2012; 31:692-706. [PubMed: 22124325]

Hagen KA, Moses CT, Drasler EF, Podetz-Pedersen KM, Jameson SC, Khoruts A. A role for CD28 in lymphopenia-induced proliferation of CD4 T cells. Journal of Immunology. 2004; 173:3909-3915.

Haluszczak C, Akue AD, Hamilton SE, Johnson LD, Pujanauski L, Teodorovic L, et al. The antigenspecific CD8+ T cell repertoire in unimmunized mice includes memory phenotype cells bearing markers of homeostatic expansion. The Journal of Experimental Medicine. 2009; 206:435-448. [PubMed: 19188498] 
Hamilton SE, Jameson SC. The nature of the lymphopenic environment dictates protective function of homeostatic-memory CD8+ T cells. Proceedings of the National Academy of Sciences of the United States of America. 2008; 105:18484-18489. [PubMed: 19020089]

Hamilton SE, Wolkers MC, Schoenberger SP, Jameson SC. The generation of protective memory-like CD8(+) T cells during homeostatic proliferation requires CD4(+) T cells. Nature Immunology. 2006; 7:475-481. [PubMed: 16604076]

Hirose S, Touma M, Go R, Katsuragi Y, Sakuraba Y, Gondo Y, et al. Bcl11b prevents the intrathymic development of innate CD8 T cells in a cell intrinsic manner. International Immunology. 2014

Hogquist KA, Jameson SC. The self-obsession of T cells: How TCR signaling thresholds affect fate decisions in the thymus and effector function in the periphery. Nature Immunology. 2014; 15:815823. in press. [PubMed: 25137456]

$\mathrm{Hu}$ HM, Poehlein CH, Urba WJ, Fox BA. Development of antitumor immune responses in reconstituted lymphopenic hosts. Cancer Research. 2002; 62:3914-3919. [PubMed: 12124318]

Jameson SC. Maintaining the norm: T-cell homeostasis. Nature Reviews. Immunology. 2002; 2:547556.

Jiang Q, Li WQ, Aiello FB, Mazzucchelli R, Asefa B, Khaled AR, et al. Cell biology of IL-7, a key lymphotrophin. Cytokine \& Growth Factor Reviews. 2005; 16:513-533. [PubMed: 15996891]

Johnson LD, Jameson SC. Self-specific CD8+ T cells maintain a semi-naive state following lymphopenia-induced proliferation. Journal of Immunology. 2010; 184:5604-5611.

Jordan MS, Smith JE, Burns JC, Austin JE, Nichols KE, Aschenbrenner AC, et al. Complementation in trans of altered thymocyte development in mice expressing mutant forms of the adaptor molecule SLP76. Immunity. 2008; 28:359-369. [PubMed: 18342008]

Kamimura D, Bevan MJ. Naive CD8+ T cells differentiate into protective memory-like cells after IL-2 anti IL-2 complex treatment in vivo. The Journal of Experimental Medicine. 2007; 204:18031812. [PubMed: 17664293]

Kieper WC, Burghardt JT, Surh CD. A role for TCR affinity in regulating naive T cell homeostasis. Journal of Immunology. 2004; 172:40-44.

Kieper WC, Jameson SC. Homeostatic expansion and phenotypic conversion of naive T cells in response to self peptide/MHC ligands. Proceedings of the National Academy of Sciences of the United States of America. 1999; 96:13306-13311. [PubMed: 10557316]

Kieper WC, Tan JT, Bondi-Boyd B, Gapin L, Sprent J, Ceredig R, et al. Overexpression of interleukin (IL)-7 leads to IL-15-independent generation of memory phenotype CD8+ T cells. The Journal of Experimental Medicine. 2002; 195:1533-1539. [PubMed: 12070281]

Kieper WC, Troy A, Burghardt JT, Ramsey C, Lee JY, Jiang HQ, et al. Recent immune status determines the source of antigens that drive homeostatic T cell expansion. Journal of Immunology. 2005; 174:3158-3163.

Kim PJ, Pai SY, Brigl M, Besra GS, Gumperz J, Ho IC. GATA-3 regulates the development and function of invariant NKT cells. Journal of Immunology. 2006; 177:6650-6659.

Kirberg J, Berns A, von Boehmer H. Peripheral T cell survival requires continual ligation of the T cell receptor to major histocompatibility complex-encoded molecules. Journal of Experimental Medicine. 1997; 186:1269-1275. [PubMed: 9334366]

Klebanoff CA, Khong HT, Antony PA, Palmer DC, Restifo NP. Sinks, suppressors and antigen presenters: How lymphodepletion enhances T cell-mediated tumor immunotherapy. Trends in Immunology. 2005; 26:111-117. [PubMed: 15668127]

Knudson KM, Hamilton SE, Daniels MA, Jameson SC, Teixeiro E. Cutting edge: The signals for the generation of T cell memory are qualitatively different depending on TCR ligand strength. Journal of Immunology. 2013; 191:5797-5801.

Kovalovsky D, Uche OU, Eladad S, Hobbs RM, Yi W, Alonzo E, et al. The BTB-zinc finger transcriptional regulator PLZF controls the development of invariant natural killer T cell effector functions. Nature Immunology. 2008; 9:1055-1064. [PubMed: 18660811]

Kurzweil V, Laroche A, Oliver PM. Increased peripheral IL-4 leads to an expanded virtual memory CD8+ population. Journal of Immunology. 2014; 192:5643-5651.

Kwon SJ, Crespo-Barreto J, Zhang W, Wang T, Kim DS, Krensky A, et al. KLF13 cooperates with cMaf to regulate IL-4 expression in CD4+ T cells. Journal of Immunology. 2014; 192:5703-5709. 
La Gruta NL, Rothwell WT, Cukalac T, Swan NG, Valkenburg SA, Kedzierska K, et al. Primary CTL response magnitude in mice is determined by the extent of naive $\mathrm{T}$ cell recruitment and subsequent clonal expansion. The Journal of Clinical Investigation. 2010; 120:1885-1894. [PubMed: 20440073]

Lai D, Zhu J, Wang T, Hu-Li J, Terabe M, Berzofsky JA, et al. KLF13 sustains thymic memory-like CD8(+) T cells in BALB/c mice by regulating IL-4-generating invariant natural killer T cells. The Journal of Experimental Medicine. 2011; 208:1093-1103. [PubMed: 21482696]

Lauritsen JP, Wong GW, Lee SY, Lefebvre JM, Ciofani M, Rhodes M, et al. Marked induction of the helix-loop-helix protein Id3 promotes the gammadelta $\mathrm{T}$ cell fate and renders their functional maturation Notch independent. Immunity. 2009; 31:565-575. [PubMed: 19833086]

Le Campion A, Bourgeois C, Lambolez F, Martin B, Leaument S, Dautigny N, et al. Naive T cells proliferate strongly in neonatal mice in response to self-peptide/self-MHC complexes. Proceedings of the National Academy of Sciences of the United States of America. 2002; 99:4538-4543. [PubMed: 11917110]

Lee JY, Hamilton SE, Akue AD, Hogquist KA, Jameson SC. Virtual memory CD8 T cells display unique functional properties. Proceedings of the National Academy of Sciences of the United States of America. 2013; 110:13498-13503. [PubMed: 23898211]

Lee YJ, Holzapfel KL, Zhu J, Jameson SC, Hogquist KA. Steady-state production of IL-4 modulates immunity in mouse strains and is determined by lineage diversity of iNKT cells. Nature Immunology. 2013; 14:1146-1154. [PubMed: 24097110]

Lee YJ, Jameson SC, Hogquist KA. Alternative memory in the CD8 T cell lineage. Trends in Immunology. 2011; 32:50-56. [PubMed: 21288770]

Lee YJ, Jeon YK, Kang BH, Chung DH, Park CG, Shin HY, et al. Generation of PLZF+ CD4+ T cells via MHC class II-dependent thymocyte-thymocyte interaction is a physiological process in humans. The Journal of Experimental Medicine. 2010; 207(237-246):S231-S237.

Lees RK, Ferrero I, MacDonald HR. Tissue-specific segregation of TCRgamma delta+NKT cells according to phenotype TCR repertoire and activation status: Parallels with TCR alphabeta+ NKT cells. European Journal of Immunology. 2001; 31:2901-2909. [PubMed: 11592065]

Li W, Kim MG, Gourley TS, McCarthy BP, Sant'Angelo DB, Chang CH. An alternate pathway for CD4 T cell development: Thymocyte-expressed MHC class II selects a distinct T cell population. Immunity. 2005; 23:375-386. [PubMed: 16226503]

Li Q, Rao RR, Araki K, Pollizzi K, Odunsi K, Powell JD, et al. A central role for mTOR kinase in homeostatic proliferation induced CD8+ T cell memory and tumor immunity. Immunity. 2011; 34:541-553. [PubMed: 21511183]

Li W, Sofi MH, Rietdijk S, Wang N, Terhorst C, Chang CH. The SLAM-associated protein signaling pathway is required for development of CD4+ T cells selected by homotypic thymocyte interaction. Immunity. 2007; 27:763-774. [PubMed: 18031696]

Markiewicz MA, Girao C, Opferman JT, Sun J, Hu Q, Agulnik AA, et al. Long-term T cell memory requires the surface expression of self-peptide/major histocompatibility complex molecules. Proceedings of the National Academy of Sciences of the United States of America. 1998; 95:3065-3070. [PubMed: 9501216]

Martin B, Bourgeois C, Dautigny N, Lucas B. On the role of MHC class II molecules in the survival and lymphopenia-induced proliferation of peripheral CD4+ T cells. Proceedings of the National Academy of Sciences of the United States of America. 2003; 100:6021-6026. [PubMed: 12719530]

Mazzucchelli R, Durum SK. Interleukin-7 receptor expression: Intelligent design. Nature Reviews. Immunology. 2007; 7:144-154.

Michel ML, Mendes-da-Cruz D, Keller AC, Lochner M, Schneider E, Dy M, et al. Critical role of ROR-gammat in a new thymic pathway leading to IL-17-producing invariant NKT cell differentiation. Proceedings of the National Academy of Sciences of the United States of America. 2008; 105:19845-19850. [PubMed: 19057011]

Min B, Foucras G, Meier-Schellersheim M, Paul WE. Spontaneous proliferation, a response of naive CD4 T cells determined by the diversity of the memory cell repertoire. Proceedings of the National 
Academy of Sciences of the United States of America. 2004; 101:3874-3879. [PubMed: 15001705]

Min HS, Lee YJ, Jeon YK, Kim EJ, Kang BH, Jung KC, et al. MHC class II-restricted interaction between thymocytes plays an essential role in the production of innate CD8+ T cells. Journal of Immunology. 2011; 186:5749-5757.

Min B, McHugh R, Sempowski GD, Mackall C, Foucras G, Paul WE. Neonates support lymphopeniainduced proliferation. Immunity. 2003; 18:131-140. [PubMed: 12530982]

Min B, Paul WE. Endogenous proliferation: Burst-like CD4 T cell proliferation in lymphopenic settings. Seminars in Immunology. 2005; 17:201-207. [PubMed: 15826825]

Min B, Yamane H, Hu-Li J, Paul WE. Spontaneous and homeostatic proliferation of CD4 T cells are regulated by different mechanisms. Journal of Immunology. 2005; 174:6039-6044.

Mold JE, McCune JM. Immunological tolerance during fetal development: From mouse to man. Advances in Immunology. 2012; 115:73-111. [PubMed: 22608256]

Moon JJ, Chu HH, Pepper M, McSorley SJ, Jameson SC, Kedl RM, et al. Naive CD4(+) T cell frequency varies for different epitopes and predicts repertoire diversity and response magnitude. Immunity. 2007; 27:203-213. [PubMed: 17707129]

Morris SC, Heidorn SM, Herbert DR, Perkins C, Hildeman DA, Khodoun MV, et al. Endogenously produced IL-4 nonredundantly stimulates CD8+ T cell proliferation. Journal of Immunology. 2009; 182:1429-1438.

Moses CT, Thorstenson KM, Jameson SC, Khoruts A. Competition for self ligands restrains homeostatic proliferation of naive CD4 T cells. Proceedings of the National Academy of Sciences of the United States of America. 2003; 100:1185-1190. [PubMed: 12525694]

Murali-Krishna K, Ahmed R. Cutting edge: Naive T cells masquerading as memory cells. Journal of Immunology. 2000; 165:1733-1737.

Muranski P, Chmielowski B, Ignatowicz L. Mature CD4+ T cells perceive a positively selecting class II MHC/peptide complex in the periphery. Journal of Immunology. 2000; 164:3087-3094.

Nayar R, Enos M, Prince A, Shin H, Hemmers S, Jiang JK, et al. TCR signaling via Tec kinase ITK and interferon regulatory factor 4 (IRF4) regulates CD8+ T-cell differentiation. Proceedings of the National Academy of Sciences of the United States of America. 2012; 109:E2794-E2802. [PubMed: 23011795]

Nesic D, Vukmanovic S. MHC class I is required for peripheral accumulation of CD8+ thymic emigrants. Journal of Immunology. 1998; 160:3705-3712.

Oliver PM, Cao X, Worthen GS, Shi P, Briones N, MacLeod M, et al. Ndfip1 protein promotes the function of itch ubiquitin ligase to prevent $\mathrm{T}$ cell activation and $\mathrm{T}$ helper 2 cell-mediated inflammation. Immunity. 2006; 25:929-940. [PubMed: 17137798]

Oliver JA, Stolberg VR, Chensue SW, King PD. IL-4 acts as a potent stimulator of IFN-gamma expression in CD8+ T cells through STAT6-dependent and independent induction of Eomesodermin and T-bet. Cytokine. 2012; 57:191-199. [PubMed: 22078635]

Palmer MJ, Mahajan VS, Chen J, Irvine DJ, Lauffenburger DA. Signaling thresholds govern heterogeneity in IL-7-receptor-mediated responses of naive CD8(+) T cells. Immunology and Cell Biology. 2011; 89:581-594. [PubMed: 21339767]

Park JH, Yu Q, Erman B, Appelbaum JS, Montoya-Durango D, Grimes HL, et al. Suppression of IL7Ralpha transcription by IL-7 and other prosurvival cytokines: A novel mechanism for maximizing IL-7-dependent T cell survival. Immunity. 2004; 21:289-302. [PubMed: 15308108]

Pereira RM, Martinez GJ, Engel I, Cruz-Guilloty F, Barboza BA, Tsagaratou A, et al. Jarid2 is induced by TCR signalling and controls iNKT cell maturation. Nature Communications. 2014; 5:4540.

Posevitz V, Arndt B, Krieger T, Warnecke N, Schraven B, Simeoni L. Regulation of T cell homeostasis by the transmembrane adaptor protein SIT. Journal of Immunology. 2008; 180:1634-1642.

Qi Q, Xia M, Hu J, Hicks E, Iyer A, Xiong N, et al. Enhanced development of CD4+ gammadelta T cells in the absence of Itk results in elevated IgE production. Blood. 2009; 114:564-571.

[PubMed: 19443662] 
Rao RR, Li Q, Odunsi K, Shrikant PA. The mTOR kinase determines effector versus memory CD8+ T cell fate by regulating the expression of transcription factors T-bet and Eomesodermin. Immunity. 2010; 32:67-78. [PubMed: 20060330]

Renkema KR, Li G, Wu A, Smithey MJ, Nikolich-Zugich J. Two separate defects affecting true naive or virtual memory $\mathrm{T}$ cell precursors combine to reduce naive $\mathrm{T}$ cell responses with aging. Journal of Immunology. 2014; 192:151-159.

Rudd BD, Venturi V, Li G, Samadder P, Ertelt JM, Way SS, et al. Nonrandom attrition of the naive CD8+ T-cell pool with aging governed by T-cell receptor: pMHC interactions. Proceedings of the National Academy of Sciences of the United States of America. 2011; 108:13694-13699. [PubMed: 21813761]

Sandau MM, Winstead CJ, Jameson SC. IL-15 is required for sustained lymphopenia-driven proliferation and accumulation of CD8 T cells. Journal of Immunology. 2007; 179:120-125.

Savage AK, Constantinides MG, Han J, Picard D, Martin E, Li B, et al. The transcription factor PLZF directs the effector program of the NKT cell lineage. Immunity. 2008; 29:391-403. [PubMed: 18703361]

Schluns KS, Kieper WC, Jameson SC, Lefrancois L. Interleukin-7 mediates the homeostasis of naive and memory CD8 T cells in vivo. Nature Immunology. 2000; 1:426-432. [PubMed: 11062503]

Schluns KS, Lefrancois L. Cytokine control of memory T-cell development and survival. Nature Reviews. Immunology. 2003; 3:269-279.

Schuler T, Hammerling GJ, Arnold B. Cutting edge: IL-7-dependent homeostatic proliferation of $\mathrm{CD} 8+\mathrm{T}$ cells in neonatal mice allows the generation of long-lived natural memory $\mathrm{T}$ cells. Journal of Immunology. 2004; 172:15-19.

Seddon B, Legname G, Tomlinson P, Zamoyska R. Long-term survival but impaired homeostatic proliferation of naive T cells in the absence of p56lck. Science. 2000; 290:127-131. [PubMed: 11021796]

Seddon B, Zamoyska R. TCR and IL-7 receptor signals can operate independently or synergize to promote lymphopenia-induced expansion of naive T cells. Journal of Immunology. 2002a; 169:3752-3759.

Seddon B, Zamoyska R. TCR signals mediated by Src family kinases are essential for the survival of naive T cells. Journal of Immunology. 2002b; 169:2997-3005.

Sharma A, Chen Q, Nguyen T, Yu Q, Sen JM. T cell factor-1 and beta-catenin control the development of memory-like CD8 thymocytes. Journal of Immunology. 2012; 188:3859-3868.

Shedlock DJ, Shen H. Requirement for CD4 T cell help in generating functional CD8 T cell memory. Science. 2003; 300:337-339. [PubMed: 12690201]

Singh NJ, Schwartz RH. The lymphopenic mouse in immunology: From patron to pariah. Immunity. 2006; 25:851-855. [PubMed: 17174925]

Sintes J, Cuenca M, Romero X, Bastos R, Terhorst C, Angulo A, et al. Cutting edge: Ly9 (CD229), a SLAM family receptor, negatively regulates the development of thymic innate memory-like CD8+ T and invariant NKT cells. Journal of Immunology. 2013; 190:21-26.

Skon CN, Jameson SC. Fox factors fight over T cell quiescence. Nature Immunology. 2011; 12:522524. [PubMed: 21587312]

Smith K, Seddon B, Purbhoo MA, Zamoyska R, Fisher AG, Merkenschlager M. Sensory adaptation in naive peripheral CD4 T cells. The Journal of Experimental Medicine. 2001; 194:1253-1261. [PubMed: 11696591]

Sosinowski T, White JT, Cross EW, Haluszczak C, Marrack P, Gapin L, et al. CD8alpha+dendritic cell trans presentation of IL-15 to naive CD8+ T cells produces antigen-inexperienced T cells in the periphery with memory phenotype and function. Journal of Immunology. 2013; 190:19361947.

Sprent J, Surh CD. Normal T cell homeostasis: The conversion of naive cells into memory-phenotype cells. Nature Immunology. 2011; 12:478-484. [PubMed: 21739670]

Su LF, Davis MM. Antiviral memory phenotype T cells in unexposed adults. Immunological Reviews. 2013; 255:95-109. [PubMed: 23947350]

Su LF, Kidd BA, Han A, Kotzin JJ, Davis MM. Virus-specific CD4 (+) memory-phenotype T cells are abundant in unexposed adults. Immunity. 2013; 38:373-383. [PubMed: 23395677] 
Sun JC, Bevan MJ. Defective CD8 T cell memory following acute infection without CD4 T cell help. Science. 2003; 300:339-342. [PubMed: 12690202]

Surh CD, Sprent J. Homeostasis of naive and memory T cells. Immunity. 2008; 29:848-862. [PubMed: 19100699]

Takada K, Jameson SC. Naive T cell homeostasis: From awareness of space to a sense of place. Nature Reviews. Immunology. 2009; 9:823-832.

Takeda S, Rodewald HR, Arakawa H, Bluethmann H, Shimizu T. MHC class II molecules are not required for survival of newly generated $\mathrm{CD} 4^{+} \mathrm{T}$ cells, but affect their long-term life span. Immunity. 1996; 5:217-228. [PubMed: 8808677]

Tan JT, Ernst B, Kieper WC, LeRoy E, Sprent J, Surh CD. Interleukin (IL)-15 and IL-7 jointly regulate homeostatic proliferation of memory phenotype CD8+ cells but are not required for memory phenotype CD4+ cells. The Journal of Experimental Medicine. 2002; 195:1523-1532. [PubMed: 12070280]

Tanchot C, Le Campion A, Leaument S, Dautigny N, Lucas B. Naive CD4 (+) lymphocytes convert to anergic or memory-like cells in T cell-deprived recipients. European Journal of Immunology. 2001; 31:2256-2265. [PubMed: 11477537]

Tchao NK, Turka LA. Lymphodepletion and homeostatic proliferation: Implications for transplantation. American Journal of Transplantation: Official Journal of the American Society of Transplantation and the American Society of Transplant Surgeons. 2012; 12:1079-1090.

Teixeiro E, Daniels MA, Hamilton SE, Schrum AG, Bragado R, Jameson SC, et al. Different T cell receptor signals determine CD8+ memory versus effector development. Science. 2009; 323:502505. [PubMed: 19164748]

Troy AE, Shen H. Cutting edge: Homeostatic proliferation of peripheral T lymphocytes is regulated by clonal competition. Journal of Immunology. 2003; 170:672-676.

Ueda-Hayakawa I, Mahlios J, Zhuang Y. Id3 restricts the developmental potential of gamma delta lineage during thymopoiesis. Journal of Immunology. 2009; 182:5306-5316.

Ventre E, Brinza L, Schicklin S, Mafille J, Coupet CA, Marcais A, et al. Negative regulation of NKG2D expression by IL-4 in memory CD8 T cells. Journal of Immunology. 2012; 189:3480 3489.

Verykokakis M, Boos MD, Bendelac A, Adams EJ, Pereira P, Kee BL. Inhibitor of DNA binding 3 limits development of murine slam-associated adaptor protein-dependent "innate" gammadelta T cells. PLoS One. 2010; 5:e9303. [PubMed: 20174563]

Verykokakis M, Boos MD, Bendelac A, Kee BL. SAP protein-dependent natural killer T-like cells regulate the development of CD8(+) T cells with innate lymphocyte characteristics. Immunity. 2010; 33:203-215. [PubMed: 20674402]

Verykokakis M, Krishnamoorthy V, Iavarone A, Lasorella A, Sigvardsson M, Kee BL. Essential functions for ID proteins at multiple checkpoints in invariant NKT cell development. Journal of Immunology. 2013; 191:5973-5983.

Viret C, Wong FS, Janeway CA Jr. Designing and maintaining the mature TCR repertoire: The continuum of self-peptide:self-MHC complex recognition. Immunity. 1999; 10:559-568. [PubMed: 10367901]

Vos Q, Jones LA, Kruisbeek AM. Mice deprived of exogenous antigenic stimulation develop a normal repertoire of functional T cells. Journal of Immunology. 1992; 149:1204-1210.

Wang LX, Li R, Yang G, Lim M, O'Hara A, Chu Y, et al. Interleukin-7-dependent expansion and persistence of melanoma-specific T cells in lymphodepleted mice lead to tumor regression and editing. Cancer Research. 2005; 65:10569-10577. [PubMed: 16288050]

Watarai H, Sekine-Kondo E, Shigeura T, Motomura Y, Yasuda T, Satoh R, et al. Development and function of invariant natural killer T cells producing T(h)2-and T(h)17-cytokines. PLoS Biology. 2012; 10:e1001255. [PubMed: 22346732]

Weinreich MA, Odumade OA, Jameson SC, Hogquist KA. T cells expressing the transcription factor PLZF regulate the development of memory-like CD8+ T cells. Nature Immunology. 2010; 11:709-716. [PubMed: 20601952] 
Weinreich MA, Takada K, Skon C, Reiner SL, Jameson SC, Hogquist KA. KLF2 transcription-factor deficiency in $\mathrm{T}$ cells results in unrestrained cytokine production and upregulation of bystander chemokine receptors. Immunity. 2009; 31:122-130. [PubMed: 19592277]

Wiede F, La Gruta NL, Tiganis T. PTPN2 attenuates T-cell lymphopenia-induced proliferation. Nature Communications. 2014; 5:3073.

Wiede F, Shields BJ, Chew SH, Kyparissoudis K, van Vliet C, Galic S, et al. T cell protein tyrosine phosphatase attenuates $\mathrm{T}$ cell signaling to maintain tolerance in mice. The Journal of Clinical Investigation. 2011; 121:4758-4774. [PubMed: 22080863]

Winstead CJ, Reilly CS, Moon JJ, Jenkins MK, Hamilton SE, Jameson SC, et al. CD4+ CD25+ Foxp3+ regulatory $\mathrm{T}$ cells optimize diversity of the conventional $\mathrm{T}$ cell repertoire during reconstitution from lymphopenia. Journal of Immunology. 2010; 184:4749-4760.

Workman CJ, Vignali DA. Negative regulation of T cell homeostasis by lymphocyte activation gene-3 (CD223). Journal of Immunology. 2005; 174:688-695.

Wu Z, Bensinger SJ, Zhang J, Chen C, Yuan X, Huang X, et al. Homeostatic proliferation is a barrier to transplantation tolerance. Nature Medicine. 2004; 10:87-92.

Yin CC, Cho OH, Sylvia KE, Narayan K, Prince AL, Evans JW, et al. The Tec kinase ITK regulates thymic expansion, emigration, and maturation of gammadelta NKT cells. Journal of Immunology. 2013; 190:2659-2669.

Yuan J, Nguyen CK, Liu X, Kanellopoulou C, Muljo SA. Lin28b reprograms adult bone marrow hematopoietic progenitors to mediate fetal-like lymphopoiesis. Science. 2012; 335:1195-1200. [PubMed: 22345399]

Zhou X, Yu S, Zhao DM, Harty JT, Badovinac VP, Xue HH. Differentiation and persistence of memory CD8(+) T cells depend on T cell factor 1. Immunity. 2010; 33:229-240. [PubMed: 20727791] 


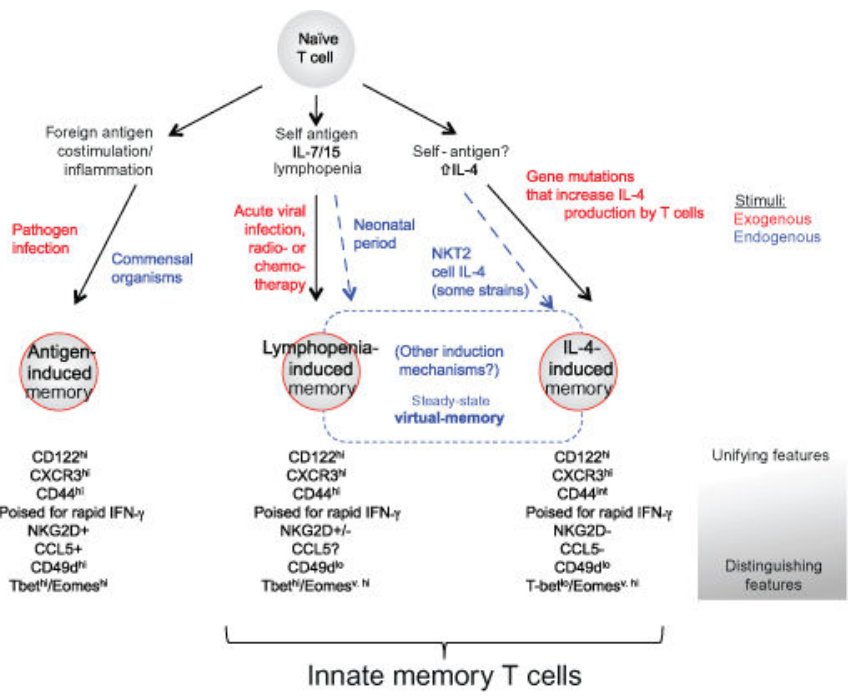

Figure 1.

Overview of generation pathways and characteristics of innate and conventional memory $\mathrm{T}$ cell populations. Naïve $\mathrm{T}$ cells can respond to a variety of endogenous and exogenous (or experimental) signals to produce memory-phenotype cells. Stimulation by foreign antigens, in a suitably immunogenic way, will produce "antigen-induced memory," while there are two pathways that produce "Innate memory" T cells: these pathways involve the response to lymphopenia or the response to IL-4. Populations of T cells with innate memory properties are found in normal animals at steady state - these are termed virtual memory cells. Key factors involved in generation of these cells and major phenotypic characteristics that are shared or distinguished these different populations are indicated. More details in the text. 


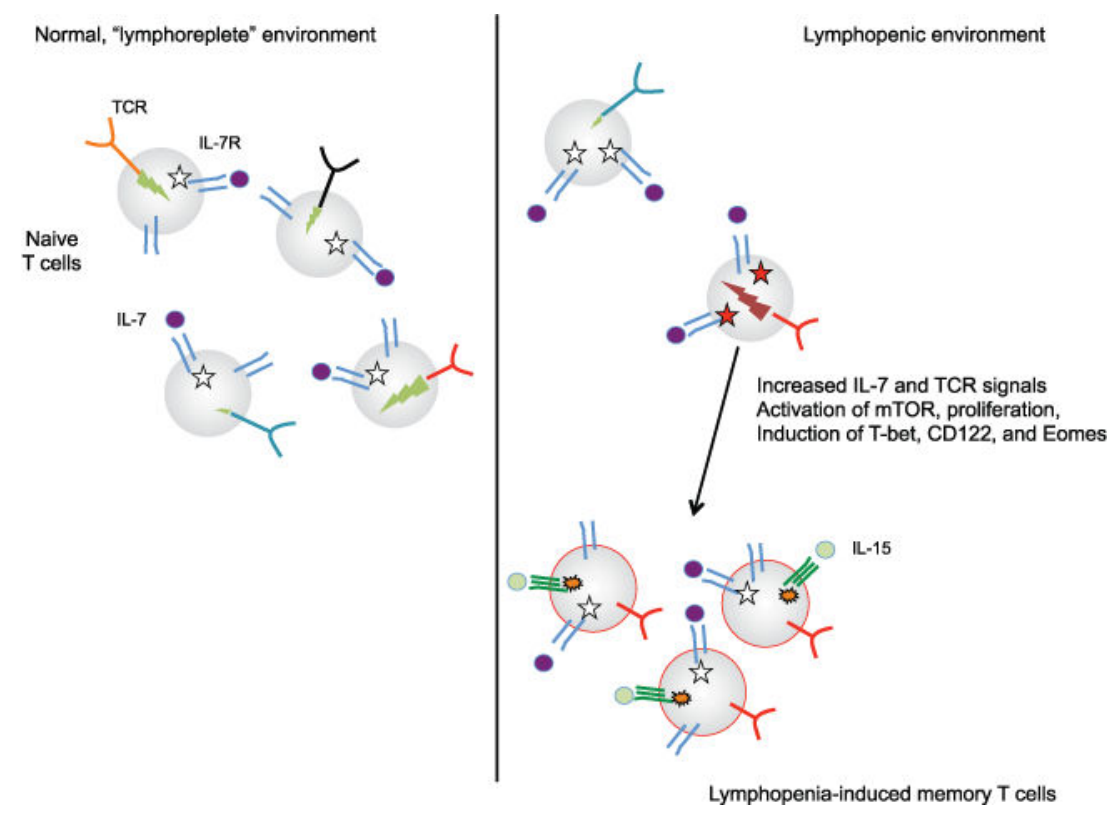

Figure 2.

Key elements in generation of lymphopenia-induced memory $\mathrm{T}$ cells. Naïve $\mathrm{T}$ cells in a normal environment (left) are maintained through basal signals through IL-7R and TCR. The intensity of IL-7R signals (indicated by white stars) is limited both by competition between $\mathrm{T}$ cells for access to IL-7 and by the fact that IL-7 signals cause reduction in IL-7Ra expression. TCR signals induced by encounter with self-peptide/-MHC ligands are also important for naïve T cell survival. The intensity of TCR signals induced by self-ligand stimulation varies for different clones (indicated by green (light gray in the print version) lightning bolts), and this correlates directly with expression of the cell surface molecule CD5 (not shown). In a lymphopenic situation (right), both IL-7R and TCR signals are enhanced and/or maintained, leading some clones (red TCR (dark gray in the print version)) to proliferate and increase expression of transcription factors and cell surface markers associated with memory cells. Other clones, with weaker basal TCR signaling (and/or lower IL-7R expression - not shown), do not respond to these cues. Maintenance of lymphopeniainduced memory cells (at least for CD8+ T cells) involves stimulation through IL-15R, which can maintain basal proliferation after IL-7R signaling reverts to normal levels. Memory T cells do not require TCR engagement for survival. 


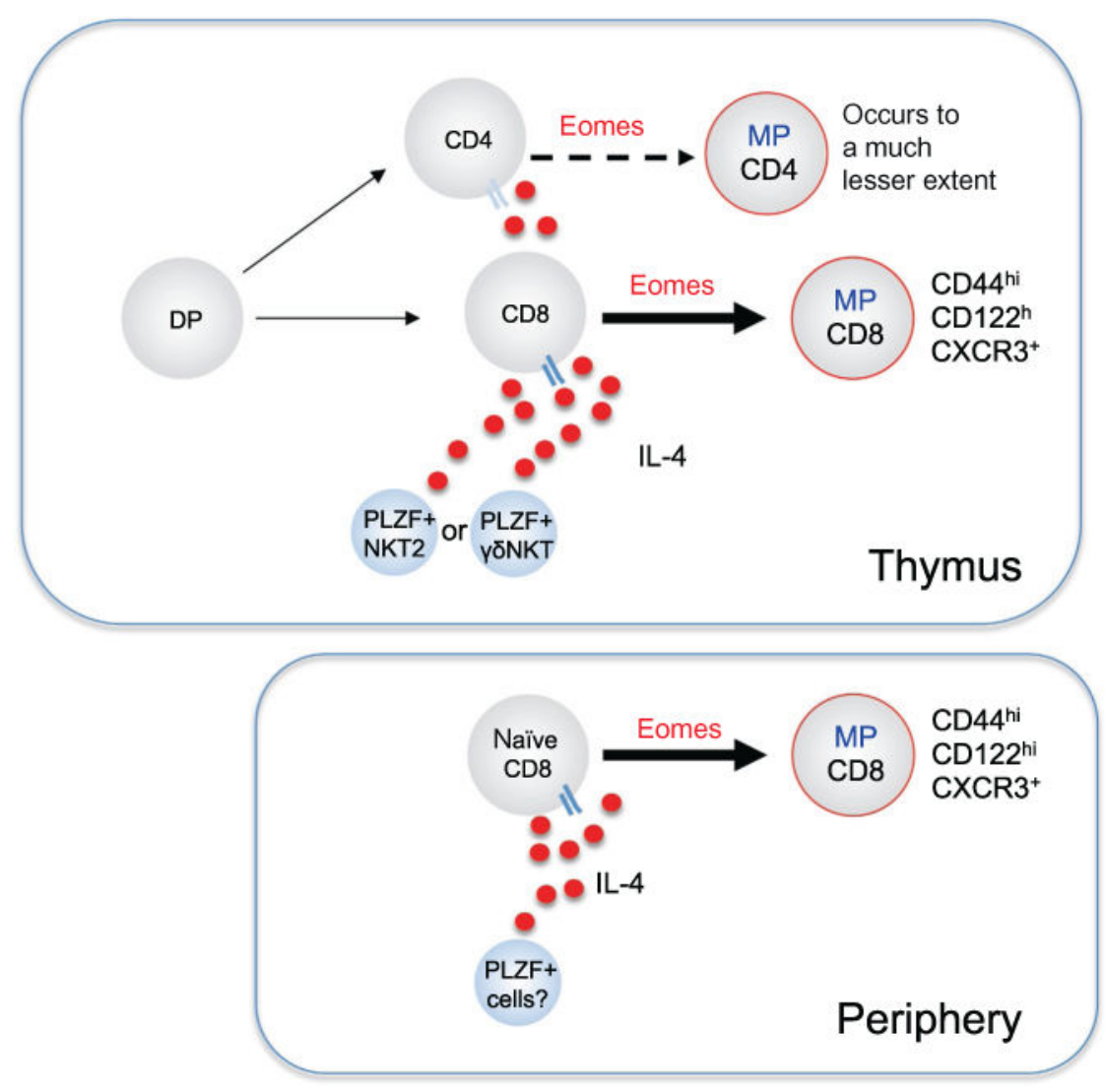

Figure 3.

Key elements in generation of IL-4-induced memory T cells. Developing thymocytes reaching the CD4+ or CD8+ SP stage respond to high levels of the cytokine IL-4 by upregulation of the transcription factor Eomes, and subsequent acquisition of memoryphenotype (MP) and memory-like functional properties. This effect is much more pronounced for CD8 than CD4 T cells. Cells expressing the transcription factor PLZF are the typical source of IL-4, and this population is comprised chiefly of a subset of iNKT cells (NKT2) or TCR $\gamma \delta$ T cells with properties similar to NKT cells $(\gamma \delta \mathrm{NKT})$. This process may not exclusively initiate in the thymus, since some models show IL-4-induced memory CD8 $\mathrm{T}$ cells arise exclusively in the peripheral lymphoid tissues. It is currently unclear whether TCR signals cooperate with IL-4R stimulation in generation of IL-4-induced memory T cells. See Table 1 for more details of genetic manipulations that influence generation of IL-4-induced memory T cells. 


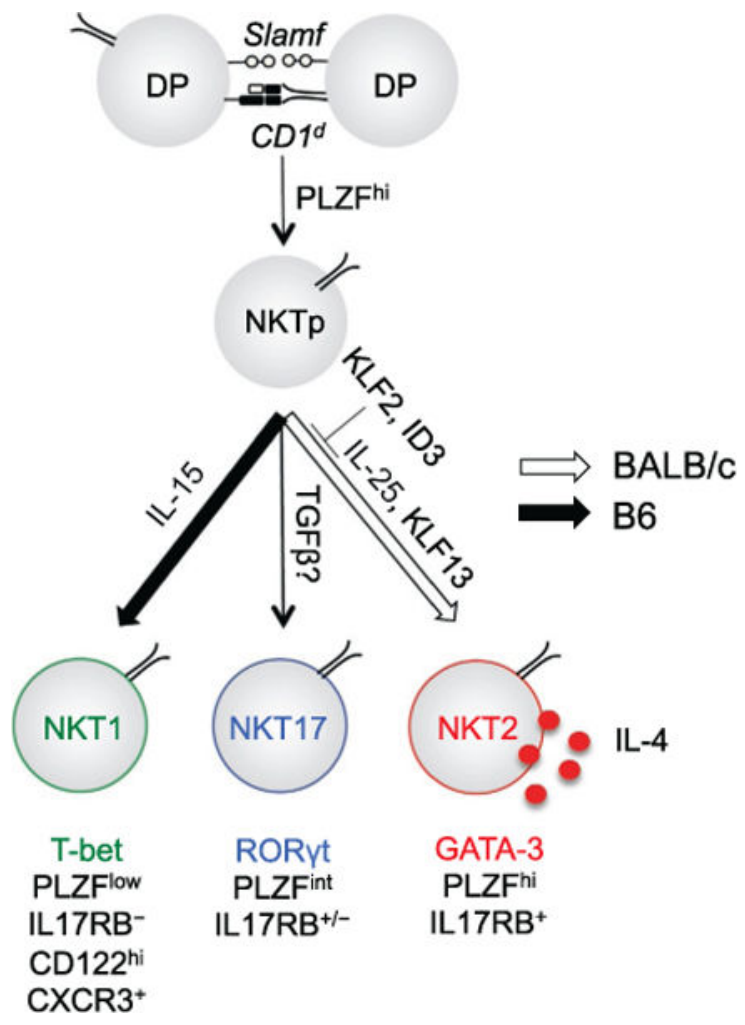

Figure 4.

Pathways involved in generation of iNKT subsets, including IL-4 producing NKT2 cells. The factors involved in generating the three distinct subsets of iNKT cells (NKT1, NKT2, and NKT17), and unique properties of those subsets, are indicated. TCR interactions with CD1d (bearing ill-defined self-glycolipid(s)) and homotypic Slam protein interactions leads CD4+CD8+ double positive (DP) thymocytes to upregulate the PLZF transcription factor and differentiate into immature NKT precursors (NKTp). In response to factors and induced transcription factors indicated, these cells differentiate into NKT1, NKT2, or NKT17 populations, bearing distinct phenotypic markers, levels of PLZF, and functional properties. The NKT2 population produces IL-4 at steady state and, if present in suitable numbers, can promote differentiation of IL-4-induced memory $\mathrm{T}$ cells in the thymus. This population naturally occurs in abundance in BALB/c strain mice, but is much more rare in C57BL/6 strain mice: these strain-specific differences may involve the relative expression of indicated factors. 


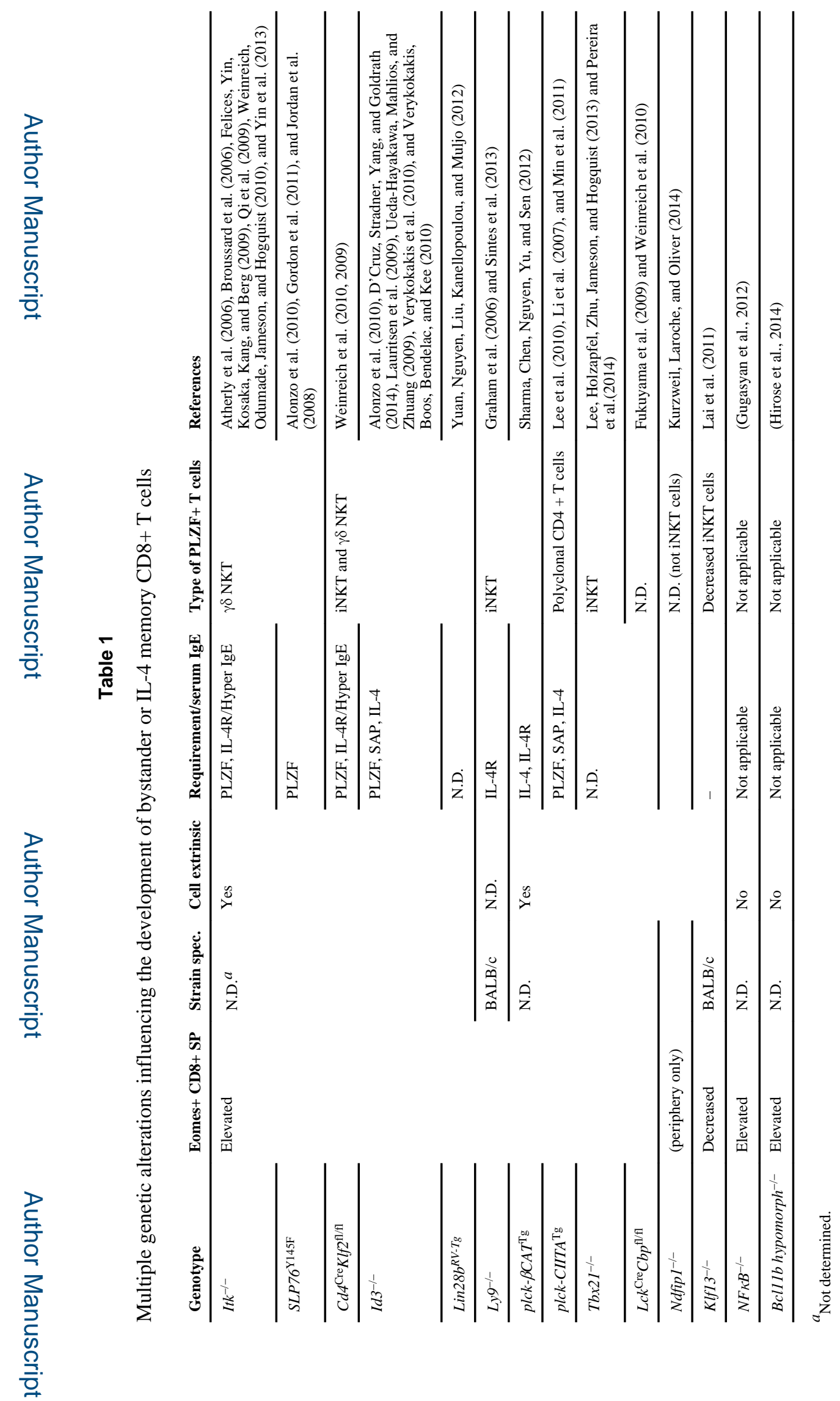

Adv Immunol. Author manuscript; available in PMC 2015 December 05. 